\title{
Employment, Wages and Voter Turnout
}

\author{
Kerwin Kofi Charles \\ University of Chicago \\ and NBER
}

\author{
Melvin Stephens, Jr. \\ University of Michigan
}

and NBER

\begin{abstract}
Using county-level data across several decades, and various OLS and TSLS models, we find that higher local wages and employment lower turnout in elections for Governor, Senator, U.S. Congress and State House of Representatives, but have no effect on presidential turnout. We also find that the share of people voting in one election but not in another on the same ballot increases as local labor market conditions improve. We argue that these results are most consistent with information-based models of voting, and use individual level panel data to show that increased employment lowers media usage and political knowledge.
\end{abstract}

JEL Codes D72, D80, J22

Keywords: Voting, Information, Time Allocation

\footnotetext{
We thank seminar participants at MIT, Yale, Princeton, University of Chicago, Cornell, University of Kentucky, the University of Illinois - Urbana Champaign, UC-Berkeley, Brown, the Political Economy in Chicago 2009 Conference, Wharton, Michigan State, Western Michigan, Syracuse, University of Miami, Columbia, Duke, UCLA, and numerous persons from whom we have received valuable feedback. We are especially grateful to the editor and two anonymous referees for their very helpful comments.
} 


\section{Introduction}

Social scientists have had a longstanding interest in voter turnout. Turnout is generally thought to be an indicator of levels of civic engagement, social connectedness and trust in a society (Putnam 2002). High turnout levels ensure that decisions about political leadership are made by a representative group of citizens and not only by elites (Lijphart 1997). Models of "political business cycle" (Nordhaus 1975) argue that decisions about economic policy are made with an eye to the anticipated future reaction of voters at the polls, and there is some evidence that turnout levels affect economic inequality and redistributive policies (Mueller and Stratmann 2003). Not surprisingly, there is a large literature studying the effect of a host of factors on turnout. ${ }^{1}$ However, apart from a small older literature in political science, ${ }^{2}$ a question that has received relatively little attention in this vast literature, is whether citizens are more or less likely to vote when wages are high and jobs plentiful. Moreover, because of endogeneity and measurement concerns, it is difficult to draw casual inferences from the few previous papers on this question. This paper presents evidence about the causal effect of labor market activity on voter turnout. In addition, we attempt to determine what theoretical account best explains the results we document.

The relative absence of work studying the effect of labor market activity on turnout is somewhat puzzling. As we discuss at greater length later, various theoretical models of voting suggest that turnout should be affected by the performance of the labor market. In addition, there is an active research program on "economic voting", which relates the incumbent's share of all votes cast to measures of labor market activity, to test the idea that the performance of the labor market affects people's views about the quality of the incumbent as a steward of economic affairs. ${ }^{3}$ But the observed relationship between measures of labor market activity and the share of votes received by a particular candidate reflects not only how labor market conditions affect the views of those who vote, but also how market conditions affect whether people with particular views vote in the first place. Because papers on economic voting do not study turnout directly, it is not obvious that

\footnotetext{
${ }^{1}$ This literature includes work studying demographic variables like population size and fragmentation (Mueller 2003; Blais and Dobrzynska 1998); election closeness (Kirchgassner and Himmern 1997); registration requirements (Ashenfelter and Kelly 1975); campaign spending (Ansolabehere et al. 1994); and the media (Gentzkow 2005; Lassen 2005; Dellavigna and Kaplan 2007; Gentzkow, Shapiro, and Sinkinson 2011; and Stromberg 2004)

${ }^{2}$ See Arcelus and Meltzer (1975), Wolfinger and Rosenstone (1980), Rosenstone (1982), Southwell (1988) and Radcliff (1992).

${ }^{3}$ See Lewis-Beck and Stegmaier (2000), and Hibbs (2005) for reviews of the economic voting literature. The notion that economic activity affects voters' views about candidate quality has been sharply criticized as being inconsistent with rational behavior on the part of voters (Stigler 1973, 1979).
} 
estimates from these studies capture the effect they intend to. Finally, in recent years there has been a spate of research studying how economic activity affects things like fertility decisions (Dehejia and Llera-Munery 2004), children's schooling outcomes (Ferreira and Schady 2009), mortality (Ruhm 2000), and health behaviors (Xu and Kaestner 2010). How economic activity affects voting - one of the most important actions taken in a democracy - is a natural extension of this body of work.

We study elections spanning three decades for five offices: President, Governor, Senator, U.S. Congressman and State Legislator. We use county-level data that we have assembled from various sources to estimate first-difference models, with controls for state $\times$ year fixed effects. Taking withincounty differences accounts for the effect of fixed, unobserved features of a county that are likely to affect voting, including amenities like well-funded libraries and lecture series, or the political engagement of county residents. Controlling for state-specific time effects ensures that our estimates are purged of the influence of any state-specific factors that vary across election years. One example of this type of confound might be unobserved candidate quality, which would vary with how the state is performing economically if candidates cared about their ability to raise campaign funds. Previous work studying labor market activity and turnout could not estimate model specifications similar to our preferred model because these papers have typically used aggregate state or national level data, often from a single cross-section or from a small number of years.

In addition to OLS, we estimate Two Stage Least Squares (TSLS) models to address two potential sources of bias: endogeneity bias, arising from the fact that counties experiencing improvement in labor market activity may systematically exhibit a particular type of turnout behavior; and attenuation bias, arising from the fact that difference models likely exacerbate the effect of mis-measurement of county-level labor market activity. In these TSLS models we instrument for county-level changes in the two measures of labor market activity using exogenous shocks to world oil supply, interacted with the prior importance of oil, natural gas, or coal production in the county. Shocks to international oil supplies led to sharp changes in domestic production of oil, natural gas and coal. Pre-existing differences across counties in their endowments of these resources ensured that the resulting effect on economic activity differed across counties in the same state.

When we use our county-level data to estimate regression specifications similar to those from previous studies, we reproduce the best-known finding from that work (Rosenstone 1982) that mean per capita wages and employment are associated with relatively large and strongly statistically significant positive effects on turnout. However, OLS regressions of the first-difference model with 
state $\times$ year fixed effects show that increased labor market activity lowers turnout in four of the five elections we study but not in presidential contests, where the effect is not statistically different from 0. Consistent with our expectation about the direction of bias in the OLS models, the TSLS estimates are of the same sign but larger in absolute value. Again, presidential elections are the exception, with TSLS estimates that are also not different from 0 . This pattern of results is robust to a number of robustness and specification checks, including evidence showing that the effects are unlikely to be driven by cross-state migration. The estimated effects are economically significant. For example, the TSLS estimates imply that a 10 percent increase (approximately a standard deviation) in county labor market activity between elections lowers voter turnout in gubernatorial elections by between 3 to 4 percent. Using our information about voting in many different types of elections, we examine the effect of market activity on anther dimension of turnout: the likelihood that people vote in one election, but not in another on the same ballot. We find that "roll-off" increases as labor market activity increases, across different pairs of election types for which we are able to make the comparison.

The workhorse model of voting in the economics literature is Down's (1957) classic framework. This model is consistent with the negative effects we estimate for four of the elections studied: increased labor market activity should lower turnout since higher time costs make citizens less willing to endure logistical challenges like driving to the polls or waiting in line. However, the Downs model does not explain why labor market activity has no effect on presidential turnout. Nor can it explain the finding that roll-off rises when labor market activity increases - a result that cannot be attributable to anything having to do with logistical costs, since those who fill out one part but not another of the same ballot have already paid whatever logistical costs are required to vote. What then explains our results?

One candidate explanation, we argue, might be a model in the mold of the recent work from political economy stressing the negative effect of limited information on voting. ${ }^{4}$ If the acquisition of political information, through such channels as looking at the media, is complementary with leisure then this type of model can account for the negative estimated effects for four elections. Also, if increased labor market activity has a smaller adverse effect on information in more "noteworthy" elections, where information is more ubiquitous, then a limited information model may also account for both the zero effect that we estimate for presidential elections and for our finding

\footnotetext{
${ }^{4}$ We briefly discuss these models later.
} 
that roll-off gets larger as labor market activity increases. We directly test the idea that the effects we estimate for changes in labor market activity derive from the effect of labor market activity on political information. Using data from many years of the American National Election Study, we estimate individual fixed effects models which show that, indeed, movements into non-employment are associated with a reduction in various measures of political knowledge and information, and with exposure to the media.

The remainder of the paper proceeds as follows. Section 2 describes the empirical specifications for the turnout analysis. Section 3 discusses our county-level data. Section 4 presents the countylevel results, including OLS and TSLS estimates of turnout, and the analysis of roll-off. Section 5 discusses which which class of models in the theoretical literature on voting might explain our results. In section 6 we use individual data to test the key mechanism of an argument linking voting to limited information and labor supply. Section 7 concludes.

\section{Empirical Specification for County-Level Turnout Analysis}

Suppose voter turnout, $V_{c s t}$, in a county $c$ and state $s$ for an election occurring at date $t$ is given by

$$
V_{c s t}=\beta_{0}+\beta_{1} X_{c s t}+\beta_{2} E_{c s t}^{*}+\delta_{c}+\pi_{s t}+\eta_{c s t}
$$

In (1), $X_{c s t}$ is a vector of observed county characteristics, and $\eta_{c s t}$ is an independent, mean-zero error. The vector $\delta_{c}$ of county-fixed effects represents latent, fixed county-specific determinants of turnout. The vector $\pi_{s t}$ represents state $\times$ year fixed effects that capture the effect of factors specific to a state during a given election; the quality of challengers, or the amount of advertising dollars spent in the state, are examples of this type of confound. Of course, it is only possible to control for either local effects or for state $\times$ year effects using data at a finer level of aggregation than the state.

The regressor of interest, $E_{c s t}^{*}$, represents observed measures of labor market activity in the county in the time period immediately preceding the election; the variable is starred to denote the fact that we observe error-ridden versions of the actual variables. We wish to estimate the parameter $\beta_{2}$ - the effect of variation in county labor market activity, net of what is occurring elsewhere in the state, or nationally, on voter turnout. Consider a differenced version of (1), where 
$\Delta_{c}$ represents the county-level difference between consecutive election years in a given variable:

$$
\Delta_{c} V_{c s t}=\beta_{0}+\beta_{1} \Delta_{c} X_{c s t}+\beta_{2} \Delta_{c} E_{c s t}^{*}+\Delta_{c} \pi_{s t}+\Delta_{c} \eta_{c s t} .
$$

Regression (2) is purged of the effects of any fixed county-specific factors, and controls for statespecific considerations that change across elections.

A concern about the estimate of $\beta_{2}$ from (2) is the familiar one that difference estimators exacerbate the effect of measurement error (Bound et al. 2001); mis-measurement of local labor market activity will thus lead to worse attenuation bias in the difference model (2) compared to the level regression (1). Another potential problem is that even if labor market conditions were perfectly measured, the estimate of $\beta_{2}$ from (2) will be biased if changes in local economic conditions performance are correlated with changes in unmeasured local factors that affect voting behavior $\left(\operatorname{Cov}\left(\Delta_{c} E_{c s t}^{*}, \Delta_{c} \eta_{c s t}\right) \neq 0\right)$.

A Two Stage Least Squares (TSLS) strategy, in which we instrument for $\Delta_{c} E_{c s t}^{*}$ is a way to address both any measurement error and endogenity concerns. This portion of the analysis focused on counties in states especially affected by exogenous shocks to international oil supply, over the time periods spanning the boom and bust in international oil supplies. ${ }^{5}$ Counties in these states were differentially affected by the resulting changes in national energy prices and employment in coal, gas and oil production because of differences in their endowments of these resources. We instrument for the change in county-level labor market conditions between elections using variants of

$$
\Delta R \times I(\text { county_size })
$$

where $\Delta R$ is some measure of the resource shock between election years, and $I$ (county_size) is a set of indicator variables denoting the importance of oil or coal production in the county. The resulting TSLS model estimates (2), with the change in the local labor market measure replaced by the predicted value from the regression

$$
\Delta_{c} E_{c s t}^{*}=a_{0}+a_{1} \Delta R \times I(\text { county_size })+a_{2} \Delta_{c} X_{c s t}+a_{3} \Delta_{c} \pi_{s t}+\Delta_{c} u_{c s t} .
$$

\footnotetext{
${ }^{5}$ Other authors have used energy shocks to isolate variation in local labor market outcomes - most notably Black et al (2002) who use only coal shocks in their study of disability payments. Acemoglu et al (2009) use the impact of oil price shocks on the economies of areas in the South with large oil wells to study health spending. A paper by Wolfers (2002) in the economic voting literature also uses oil price shocks. That work very much differs from our analysis in that it focuses on incumbent vote share and uses aggregate state-level data.
} 
We present the results of this first stage regression (4) before presenting the TSLS results.

\section{Data for County Turnout Analysis}

Throughout, we use two indicators of county labor market activity: log per capita earnings and log total employment per adult. The Bureau of Economic Analysis's Regional Economic Information System (REIS) provides annual county-level data on earnings and employment, beginning in 1969. Earnings include wage and salary disbursements, other labor income, and proprietors' income. The Bureau of Labor Statistics (BLS) compiles REIS wage and salary disbursements and employment data using ES-202 filings collected as part of the state unemployment insurance program. The REIS data on county wages and employment are known to be measured with some error. ${ }^{6}$ Our analysis controls for both the level and age distribution of county population. We obtain county population information disaggregated by age, sex, and race from the Census Bureau, which reports this data beginning in $1970 .{ }^{7}$ Unfortunately, population age distribution information before 1980 is limited to five-year age bands ( 0 to 4,5 to 9 , etc.). Our estimates of the number of voting age individuals in a county is therefore calculated as the number of individuals aged 20 and over.

We study five different elections using county-level data. ${ }^{8}$ These are elections for Governor, President, U.S. Senator, U.S. Congress and for the State House of Representatives. In gubernatorial, senatorial and presidential elections, all citizens in a state vote for the same set of candidates in a given election. Throughout the paper we will thus call these "state-wide" elections. In elections for the U.S. Congress or the State House of Representatives, citizens in different parts of a state vote for different candidates. We call these elections "local" elections. We assemble official county-level

\footnotetext{
${ }^{6}$ Some employers with establishments in multiple counties may only report wages and employment ES-202 information at the state-level. These reports are allocated back to counties based on their industry level distribution by county among employers reporting at the county-level, generating some measurement error. In addition, components of other labor income and proprietors income such as pension plan contributions, health and life insurance contributions, and private worker's compensation contributions are only collected at the state-level and also use an allocation rule to determine county-level totals. Documentation for REIS sources are available on-line http://www.bea.gov/regional/docs/cd.cfm

${ }^{7}$ These data are available on-line at http://www.census.gov/popest/archives/. We impute 1969 county population information by using the 1970 population data.

${ }^{8}$ We explored but ultimately did not study three other types of elections for which there is official voting data. First, states often vote on referenda concerning various issues, such as tax increases, bond sales, gay marriage, etc. However, the referenda items differ from year to year, and there are often multiple referenda on a ballot or none at all, which makes it difficult to do cross-election analysis. Second, all states but Nebraska have a state Senate. However, many of these states elected their state senators in staggered years which means that some, but not all, counties within a given state are voting for a state senator in each year. Third, there are other statewide offices such as secretary of state, state treasurer, etc. These data are not consistently collected by ICPSR, in that our data sources contain only one such office per year and the office in question may change from election to election since there was no clear standard as to which statewide office was recorded by ICSPR in a given year.
} 
voting information between 1969 and 2000 for the five types of elections from a number of sources, which we detail in the Data Appendix. Voter turnout at the county-level is constructed by dividing the total number of votes cast in an election by the Census estimate of the number of individuals ages 20 and over residing in the county.

The TSLS part of our analysis focuses on the effect of energy supply shocks in oil and coal producing counties in "coal" and "oil" states, which span the period the early 1970's to about 1990. Following Black et al. (2002), we define the "coal" states to be Kentucky, Ohio, Pennsylvania, and West Virginia - the states that span the country's large coal seam. The eleven "oil" states are those with at least 1 percent of annual state wages in the 1974 County Business Patterns (CBP) in the oil/natural gas industry. ${ }^{9}$ We create measures of the oil/natural gas and coal industry employment in these states using two-digit CBP information from 1974. We define counties as "small", "medium" or "large" producers of oil and coal based on whether their 1974 total employment share in oil and gas production or in coal is, respectively, less than $5 \%$, at least $5 \%$ and less than $20 \%$, or at least 20\%. The maps in Appendix Figure 1, which depict the distribution of "large", "medium" and "small" oil and coal producing counties, illustrate the tremendous variation in the importance of oil and coal across counties in these states. It is this variation that the TSLS analysis exploits. ${ }^{10}$

We obtain data on energy prices from the Energy Information Administration's Annual Energy Review. ${ }^{11}$ Our TSLS strategy focuses on the years 1969 to 1990, a period of two large exogenous shocks to the world oil supply: the OPEC oil embargo following the Yom Kippur War; and the period from the end of 1979 to early 1981, following the overthrowing of the Shah of Iran and the start of the Iran-Iraq War. These events affected both the prices of oil, coal and natural gas, and the employment in these industries in the U.S., as Figure 1 illustrates.

Oil prices doubled between 1973 and 1974, were stable for several years, then increased fourfold over a two year period. Prices fell sharply over the next four years to levels in the mid-1980s that were slightly lower than those of mid-1970s. Coal prices doubled between 1973 and 1976 but then fell consistently over the next two decades, returning by the late 1990s to 1970s levels. Real natural

\footnotetext{
${ }^{9}$ These states are Colorado, Kansas, Mississippi, Montana, New Mexico, North Dakota, Oklahoma, Texas, Utah, and Wyoming. As noted earlier, our analysis does not include Alaska so it is not part of this list.

${ }^{10}$ Importantly, although we characterize states as either "oil" or "coal", the empirical work measures the importance of both oil and coal in the counties in these states, regardless of whether the county is in a state we label an oil state or coal state. For example, $40 \%$ of the mining in the "coal" state of West Virginia is devoted to oil and gas. Similarly, $15 \%$ of the mining in the "oil" state of North Dakota is in coal. See Data Appendix for further details

${ }^{11}$ Oil prices are the U.S. average first purchase price per barrel, natural gas prices are the wellhead price per thousand cubic feet, and coal prices are the total price per short ton. National oil and gas industry and coal industry employment is taken from CBP data.
} 
gas prices followed a very similar pattern to that for oil prices: a fivefold increase between 1970 and the early 1980s, then a decline of more than half over the next 6 years. The second panel of the figure shows that national employment in the oil/natural gas and coal industries closely tracked the movement in prices, with the main difference that national employment was not kept artificially flat during various periods, as was true for oil prices in two periods in the 1970s because of policy decisions. ${ }^{12}$ Since changes in resource prices over our sample period are not exclusively the result of energy supply shocks, we use national employment as our main measure of the energy supply shock when constructing our instrument.

Table 1 summarizes key features about turnout, for the five types of elections. The table shows that across all elections between 1969 and 2000 and across all counties in the U.S, county presidential turnout averaged approximately $55 \%$ in our data. This was much larger than the rate in any of the other four elections studied, which ranged from $43 \%$ in gubernatorial contests to $47 \%$ in elections for Senate, across all election years. The table shows, however, that for each of these other four types of elections, turnout was appreciably larger in years where there was also a presidential election. For U.S. congressional contests, for example, turnout in non-presidential years was only $38.7 \%$, but was $51.3 \%$ for congressional elections held in presidential election years. Similar differences exist for all of the other elections.

Gubernatorial elections occur on a four year cycle, typically not coincident with the presidential election cycle. During the time period we study, gubernatorial and presidential elections occur at the same time in only nine states. Because of this non-overlap, only $20 \%$ of gubernatorial elections in our sample occur in presidential election years. Many more of the senatorial elections occur in Presidential years, but this fact should be interpreted carefully. There are two Senate seats per state, each on a staggered 6 year (even-year) cycle so that two senators from a state are typically not up for election in the same year. The six year cycle means that the election for a given seat occurs in a presidential election year once every twelve years. Elections for the U.S. House of Representative (Congress) and State House of Representatives occur on two year cycles. Thus, around half of the observations for each of these offices are from presidential election years. However, for various reasons, there are many less usable official turnout reports for State House contests compared to

\footnotetext{
${ }^{12}$ Since the early 1900s, oil production in U.S. has been overseen by various state regulatory boards, such as the Oklahoma Corporations Commission, the Louisiana Conservation Commission and, most importantly, the Texas Railroad Commission. Although the specific language outlining each board's functions and objectives differ from state to state, these agencies set limits on level of extraction and exploration in their particular states so as to stabilize price, and prevent over-exploitation of oil reserves.
} 
elections for the Congress. In the Data Appendix, we fully describe the data sources for all of the election types, and how the final samples were cleaned and assembled.

\section{County Turnout Results}

\subsection{OLS Estimates for State-Wide Elections}

Table 2 presents estimates of specifications based on equations (1) and (2) for the three "state-wide elections". This table presents results for all counties in our full sample over the period 1969-2000. The estimates in column (a) are from pooled cross-sectional regressions based on equation (1) in which county voter turnout is regressed on a county labor market measure controlling separately for state fixed effects and year fixed effects, as opposed to statexyear fixed effects, and excluding county fixed effects. Column (b) presents difference estimates based on equation (2) in which the change in county voter turnout is regressed on the change in the relevant labor market outcome, in order to account for county fixed effects. These regressions include year effects. The regressions in column (c) estimate the full specification shown in by replacing the year effects from column (b) with state $\times$ year fixed effects. The movement from (a) to (b) reflects the importance of controlling for fixed county characteristics; the movement from columns (b) to (c) shows the importance of factors specific to that particular state $\times$ year. We present results separately for elections for each of the three-wide elections: Governor, Senator and President. Finally, this and all similar tables that follow present separate results for our two measures of labor market conditions (log of per capita earnings and log of employment per adult), so each entry in the table is from a different regression.

The table shows that in pooled OLS models that control separately for state and time effects, more labor market activity in a county is associated with higher voter turnout. The estimated effects are strongly statistically significant for each of the three elections, and for both indicators of labor market activity. ${ }^{13}$ When we account for county-fixed effects in the difference estimator in column (b), the results are quite different. In particular, the positive point estimates from the level equation become negative for the gubernatorial elections in these difference models and both effects are statistically significant. For senatorial elections, both point estimates also become negative, but are only weakly significant. For presidential elections, estimating the difference model effectively

\footnotetext{
${ }^{13}$ The pooled results reproduce the finding of the work in political science which is based on more aggregate data and so does not control for unobserved fixed effects (see Rosenstone 1982). Attempts to relate labor market activity and voting using individual level data confront the problem that the paucity of individual panel data on voting which makes it difficult to control for latent person fixed effects - the analog of fixed county effects in our analysis.
} 
takes the point estimates to zero for both labor market measures. Adding state $\times$ year effects to the difference model sharply lowers the magnitude of the various effects, as shown in column (c). It is interesting that the point estimates for the gubernatorial and senatorial elections remain negative, although all are substantially reduced and only one estimate is statistically significant. For presidential elections, all of the point estimates all positive but very small. ${ }^{14}$

\subsection{Two Stage Least Squares Estimates for State-Wide Elections}

As we have described above, estimates from the difference models like (2) above might be contaminated by measurement error and endogeneity bias, which would tend to bias the negative estimates of labor market activity towards 0 (in the case of measurement error) or even through 0 (in the case of endogenity bias). ${ }^{15}$ Our TSLS analysis addresses both of these concerns.

The validity of the TSLS analysis depends on whether exogenous energy supply shocks affected changes in county labor market activity based on the importance of oil or coal production in the county. Table 3 presents the first stage regressions for counties in the oil and coal sample, with each column in the table representing a different regression. The results in panels $\mathrm{A}$ and $\mathrm{B}$ show that both oil and coal shocks (measured as the change in national employment in these industries) differentially affected changes in county log per capita earnings and log employment per adult in counties where the production of the resource was a "small", "medium" or "large" share of overall employment. ${ }^{16}$ For example, the point estimates of 0.108 and 0.281 in the first column of panel A imply that a $10 \%$ increase in national coal employment increases per capita earnings in medium and large coal counties by 1 and 3 percent, respectively, compared to small coal counties. We find similar differential effects in large and medium relative to small counties for oil supply shocks (the bottom pair of point estimates in each column); for both measures of labor market performance; and across the different years in which the all three of the state-wide elections are held. Notice also that, for all the elections, the F-statistics are all larger than the threshold of 10 that has been emphasized in the "weak instruments" literature (Staiger and Stock 1997).

\footnotetext{
${ }^{14}$ This basic pattern of results remains the same under various alternative specifications, including those in which we use the mean of labor market conditions in the two years preceding the relevant election as the measure of county labor market performance.

${ }^{15}$ Since better educated and richer people are generally more likely to vote, we would expect that counties in which income or unobserved dimensions of human capital were growing would also exhibit growth in the likelihood of voting for other reasons.

${ }^{16}$ In various robustness tests we find that the results are unaffected by the precise thresholds we use to classify production in regions.
} 
Before moving to the TSLS estimates, we present reduced form results where the change in voter turnout is regressed directly on the exogenous instruments. These results, presented in Panel C of Table 3 demonstrate two things. First, relative to "small" or "medium" counties, positive shocks to both oil and coal production significantly lowered voter turnout in "large" counties relative to "small" or "medium" counties in gubernatorial elections. The results are qualitative similar for senatorial elections, although they are not as precisely estimated. For presidential elections, however, energy shocks had no differential effect on voter turnout across counties; and coal shocks led to increased turnout but did so more in medium than in large counties.

Table 4 presents OLS and TSLS estimates of the effect of changes in the two labor market measures on the change in voter turnout for the sample of oil and coal counties over the energy boom/bust years. The TSLS estimates of labor market performance on turnout are negative and, in all but one case, strongly statistically significant for gubernatorial elections. The fact that these estimates are larger (in absolute value) than the negative OLS point estimates suggests that measurement error and endogeneity bias affect the latter results in the manner earlier described. For senatorial elections, the OLS estimates in this sample are both negative and statistically significant and, similar to the gubernatorial results, the TSLS results are also negative but larger in absolute value. The results for presidential elections are quite different. For presidential elections, both of the TSLS point estimate are positive but neither is statistically different from zero - just as was the case in the OLS results.

How large are these estimated effects? Applying the TSLS estimates to all of the counties in the full sample, the coefficient of -0.138 for log earnings per capita in the gubernatorial regressions implies that a county experiencing a one standard deviation change in log earnings per capita of $0.113 \log$ points has a reduction in voter turnout between elections of 1.6 percentage points. At our estimate of -0.318 , a county experiencing a one standard deviation change in log employment per adult of $0.061 \log$ points has a decline in voter turnout of 1.9 percentage points. Alternatively, we can estimate the impact of labor market fluctuations on voter turnout during the energy boom and bust. In large oil producing counties, log per capita earnings changed by 0.4 log points and log employment per adult by roughly 0.2 log points over the boom and bust cycle. In large coal counties, log per capita earnings changed by 0.25 log points and log employment per adult by roughly 0.1 log points. Given these swings in earnings and employment, our estimates imply that changes in labor market activity changed turnout by between 5.5 and 6.3 percentage points, respectively, in 
large oil counties and between 3.2 and 3.3 percentage points in large coal counties. Relative to the mean of $43 \%$ across all gubernatorial elections in the U.S., our implied effects are therefore quite economically significant.

\subsection{Turnout Results for Local Elections}

Table 5 presents results for the two "local" contests: the U.S. Congress and State House of Representatives elections. Panel A of the table reports results for the Congress and Panel B shows results for the State House. The first column of the table shows pooled OLS results on the all counties and years for which we have data, and the second column shows difference models with state $\times$ year fixed effects that correspond to specification (2) above. The third column and fourth columns in the table are estimated on the "oil" and "coal" counties over the boom and bust period, 1969-1990. The third column re-estimates specification (2) on this sample, and the fourth column presents TSLS results.

One important issue with the difference model specification for these elections is the time period over which the difference should be taken. Because both elections are on a two-year, evenyear cycle, changes between immediately successive elections necessarily involve one election from a presidential election year and one from a non-presidential year. Given the sharply different voting behavior we shown for all election types in presidential years, changes for these two-year elections across successive election years would involve taking the change in turnout between two elections with fundamentally different voting behavior. What we do, instead, is examine all four year differences in the data for any given seat. This ensures that all the changes in difference models for these elections are one of two types: changes between successive elections occurring in presidential years, and changes between successive elections occurring in non-presidential years. ${ }^{17}$

Table 5 shows that the results for these two local elections are remarkably similar, qualitatively, to the results presented above for the state-wide, non-presidential elections. Simple pooled OLS regression finds relatively large and strongly statistically significant positive effects of county labor market activity on turnout for both of the elections. As with the gubernatorial and senatorial elections, when we estimate county first-difference models with statexyear fixed effects, we find that changes in labor market activity lower turnout for both types of elections. The third column

\footnotetext{
${ }^{17}$ We estimated numerous alternative specifications, covering the other differences that one might take for these two year elections, including two year changes and find qualitatively similar results to those presented here. The results are available in the Online Appendix.
} 
shows a similar result in the sample of "oil" and "coal" counties over the boom and bust years of the energy shocks. The fourth column presents TSLS estimates for those counties. For the House of Representative elections, the large, and statistically significant negative point estimates are very similar to the findings for non-presidential state-wide contests. One cautionary note about TSLS estimates for both of the local elections is that, perhaps because of the states and which we have data, the instruments are considerably "weaker" than is true for the state-wide elections, as evidenced by the F-statistics which are smaller than the commonly used threshold of 10 . Despite this concern, we view these results as showing that increased labor market activity lowers voter turnout for "local" elections.

\subsection{Roll-Off Across Elections Pairs}

Our final set of county-level results is an analysis of "roll-off" - how labor market activity affects the share of people voting in one election but not another on the same ballot. Although it is well known that in any election cycle citizens vote only for a subset of elections on the ballot (Bullock and Dunn 1996), how roll-off varies with economic activity has not, to our knowledge, been previously studied.

To study roll-off we must obviously examine elections of different types occurring at the same time in a county. To implement the difference specification that is central to our analysis, we examine changes in any gap in voting across election years for different pairs of such elections. These requirements present an major challenge from the perspective of data availability. For example, studying roll-off in presidential versus gubernatorial voting is frustrated by the fact that, during the years under study, gubernatorial and presidential elections occur at the same time in only nine states. Further, many states in which gubernatorial and Presidential elections do occur at the same time are not part of our "oil" and "coal" sample, effectively ruling out any TSLS analysis. To take another example, the change in presidential versus senatorial roll off between two successive presidential years will not involve the same Senate seat because of the staggered, six year Senate cycle described earlier. Similar problems, arising from non-alignment of election timing, or limited data, affect all of the other pairwise comparisons. When the limited data do line up appropriately, it is often the case that the counties are not part of the "oil" and "coal" sample, which prevents us from doing credible TSLS analysis. What our data do allow us to do is to estimate roll-off models for several different pairs of elections using our preferred OLS county-difference model with 
state $\times$ year fixed effects.

Formally, we estimate models of the form

$$
\Delta_{c} R O_{c s t}=\alpha_{0}+\alpha_{1} \Delta_{c} X_{c s t}+\alpha_{2} \Delta_{c} \pi s t+\Delta_{c} \eta_{c s t}
$$

where $\Delta_{c} X_{c s t}, \Delta_{c} h_{c s t}^{*}$ and $\Delta_{c} \pi_{s t}$ represent, as before, changes in observed county characteristics, labor market activity measures, and state $\times$ year fixed effects and $\eta_{c s t}$ is the change in a mean-zero error. The outcome variable $R O_{c s t}$ measures roll-off between two elections for which there is, in general, a gap in voting, and equals the difference in the share of people in the county voting in the more "note-worthy" election, $e$, versus the less "noteworthy" contest, $\bar{e}$. We treat the more "note-worthy" election in a pair as that for which turnout is higher over all years for which we have data when the two elections occur simultaneously. In summary, $R O_{c s t}=V_{c s t}^{e}-V_{c s t}^{\bar{e}}$.

The top row of Table 6 shows mean roll-off across all years for different pairs of elections: the average share on people voting in the election listed first compared to the one listed listed second when both elections are on the same ballot. So for example, in presidential election years, the difference in the share of a county voting for the president versus the share voting for the U.S. Congress is 4.1 percentage points. These means show clearly that there is, in general, substantial roll-off across different types of elections. The mean gap tends to be largest for contests for which there is a clear intuitive difference in "size" or "importance". Thus, there is in general substantial roll off for all elections involving the elections for the state legislature - precisely the election that one would have guessed ex ante, that people considered the least "noteworthy" (or well-known). And, presidential voting is on average, larger than voting in other elections occurring in presidential years. One interesting observation from these means is that roll-off in some election pairs in, on average quite small: presidential versus gubernatorial roll-off in the states where these elections are at the same time in quite small, as is presidential versus senatorial voting, and senatorial versus congressional voting.

Each of the other entries in Table 6 presents results from regression (5), separately for the two measures of labor market activity, and for the particular election pair indicated in the column. These regressions are estimated on all counties over all the years for which we have data and, as in previous tables, each entry is from a different regression. Almost all of the point estimates in the table are positive, although many are only weakly statistically significant. The point estimates that are very 
small or negatively signed are for election pairs for which there is, on average, very little roll-off. Those effects that are statistically significant, like those for presidential versus congressional rolloff, or senatorial versus State Legislature roll-off, suggest effects that are not trivial. For example, the point estimate of 0.037 for the log employment per adult implies that a county experiencing a one standard deviation increases in log employment per adult would see an increase in presidential versus congressional roll-off of 0.23 percentage points. Relative to mean roll-off for this election pair of approximately 3.7 percentage points, that represents approximately a 5.5 percent increase in roll-off.

If the results from the previous regressions are a guide, these OLS difference estimates are likely downwards biased. Unfortunately, as we have noted, for most of the pairwise comparisons in Table 6 we simply do not have enough data in the "oil" and "coal" counties over the boom and bust years to conduct credible TSLS analysis, as the sample sizes are relatively small and the instruments fail conventional weak-instrument tests. The lone exception is for the presidential/congressional rolloff. For this pair of elections, the F-stats of the excluded instruments are just below conventional threshold levels. When we estimate TSLS versions of (5) for this election pair, we estimate effects for the two measures of labor market activity on roll-off that are substantially larger than the corresponding OLS results, although the estimated effect for the employment measure is only weakly statistically significant. Specifically, the TSLS point estimate for the effect of log per capita earnings is 0.091 with a standard error of 0.049 , while the point estimate for log employment per adult is 0.195 with a standard error of 0.162 . On the whole, the results in Table 6 and the one type of TSLS analysis we can conduct for presidential versus congressional voting on the same ballot strongly suggest that roll-off rises as as labor market activity increases.

\subsection{Summary of Robustness and Extensions}

We conduct a number of robustness tests and extensions of the various county level turnout results. These results are presented in the Online Appendix, but we briefly summarize them here. In one set of tests, we explore alternative specifications of the instrument, including: (a) using changes in coal and oil prices rather than national employment to define the energy shock; (b) using single digit 1967 CBP data to define the importance of oil and coal production in a county, rather than the 1974 two-digit information used in the main analysis; and (c) using the available data on coal, oil and gas production to create different measures of the importance of the production of a given 
resource in the county. Our results are essentially unchanged under these alternatives specifications of the instrumental variables.

In another set of tests, we estimate OLS models using data aggregated to levels larger than the county but still subsumed within a state. If, indeed, the preferred OLS difference specification are attenuated partly because of measurement error concerns, then OLS models using data aggregated to areas larger than counties, and thus arguably subject to less measurement error, should yield larger (in absolute value) point estimates for coefficients that are not truly 0 , as we argue the county-level TSLS models do. Reassuringly, for the most part, this is precisely what we find with these more aggregated data, again with the notable exception of presidential elections, where the results are again 0. Since these models are OLS regressions, and do not depend on the oil shock instrument in any way, there is no concern that they instruments fail an exclusion test.

Finally, we use data from the 1970, 1980 and 1990 Censuses about peoples' five year migration behavior within and across states to examine migration in the "oil" and "coal" counties over the boom and bust years. If economic shocks encourage mobility across state lines then our findings of a zero effect for Presidential elections along with negative effects for Gubernatorial and Senatorial may be driven by entrants to (and leavers from) a county being informed about Presidential candidates but not the Gubernatorial and Senatorial candidates in their destination state. We find that the vast majority of migration in response to the energy price shocks occurred across counties within states rather than between states such that the resulting magnitude of cross-state migration cannot explain our results. Unfortunately, we have no data on migration across congressional districts so cannot similarly bound the role of migration on the results in elections for the Congress and State House.

\section{Theoretical Discussion}

What theoretical argument accounts for our various county-level results? There are two arguments linking labor market activity and voter turnout in the older political science literature. The "withdrawal hypothesis" (Brody and Sniderman 1977) contends that people should be less likely to vote in bad economic times because they are more preoccupied with financial concerns at such times and so ignore political acts like voting. Our findings that increased labor market activity, for nearly all the elections we study, lowers turnout sharply reject the key prediction of this hypothesis. The second argument is the "mobilization hypothesis" (Scholzman and Verba 1979), which posits that 
voters are more likely to turn to voting to correct grievances than they are to express satisfaction, perhaps because of "negativity bias" (Lau 1982, 1985) in political behavior. Turnout should therefore decline as labor market outcomes improve, which is consistent with the effects we estimate for four of the elections. However, mobilization does not explain the statistically insignificant effect we find for presidential elections unless, for some odd reason, presidential elections - the most prominent of all elections - are the only contests for which voters are not mobilized to express their dissatisfaction.

The main model of voting in the economics and political economy traditions has been the classic Downs (1967) model. Downs' framework depicts citizens as voting only if the benefits they derive from voting exceed the logistical costs of voting, like getting to the polls or standing in line. Downs describes two types of benefits from voting: psychic benefits from the mere act of voting, such as the positive feeling someone receives from discharging their civic responsibility or from expressing their satisfaction with (or outrage about) events; and instrumentalist benefits, which the voter receives in the event that his vote in pivotal in changing the outcome of the election. Use of the Downs framework among economists to explain voting behavior has usually focused on how the variables under study affect voting costs. This focus on the cost side is not surprising. On one hand, no single citizen's vote can be pivotal in large elections, so it is natural to ignore any instrumentalist benefits from voting. In addition, explaining people's willingness to engage in an action by how much they like the action - as arguments stressing the psychic benefits of voting effectively do - is an example of the type of preference-based argument usually eschewed in economics.

Concentrating on how labor market activity affects the logistical costs of voting, the standard Downs framework can explain the negative effects we document for four of the elections studied. Increased labor market activity increases time costs, which should make citizens less willing to bear the logistical costs of voting and thus make them less likely to vote. However, like mobilization, this argument cannot explain why the estimated effect for Presidential turnout is not also negative. Even more importantly, our finding that roll-off grows as labor market activity increases cannot have anything to do with logistical costs, since person voting in one election have necessarily already incurred whatever logistical costs are necessary to vote in another election on the same ballot.

A number of recent models in political economy, which build upon and extend the standard Downs model, stress the role of limited information in determining voter turnout. These models emphasize different reasons why reduced information lowers turnout, arguing that such a link might 
arise for strategic reasons (Feddersen and Pesendorfer 1996), disutility associated with uncertainty (Matsusaka 1995), regret (Merlo 2006; Degan and Merlo 2011), or aversion to ambiguity (Ghirardato and Katz 2002; Ashworth 2011). If the acquisition of political information, through such channels as looking at the media, is complementary with leisure time, then increased labor market activity would, in general, lower turnout. Moreover, if there is variation in the degree to which political information is adversely affected by reduction in leisure time, then this negative effect can be smaller in some elections than others, and could even for zero for particular elections. This would explain not only our finding that roll-off between different pairs of more- and less-prominent elections rises as labor market activity increase, but also our finding that labor market activity has no effect on presidential turnout. ${ }^{18}$

One appealing feature of the argument that the various county-level turnout results might be jointly explained by a limited information type model is that the key aspects of the argument can be directly tested. We turn to this analysis in the next section.

\section{Individual Level Evidence on Information, Voting and Employment}

In this section, we use micro-data to test whether increased labor market activity reduces voters' exposure to political information, increases their uncertainty about some elections, and lowers turnout in those elections. We present direct evidence on such aspects of this mechanism as we are able to using individual level data.

Suppose that the individual labor supply $h_{i s t}$ of a person $i$ living in state $s$ at time $t$ is related to the various outcomes of interest $y_{\text {ist }}$ (information or knowledge, media exposure and voting) according to the regression model

$$
y_{i s t}=\lambda_{0}+\lambda_{1} h_{i s t}+\alpha_{i}+\pi_{s t}+\nu_{i s t}
$$

where $x_{i s t}$ is a vector of individual level observables, $\alpha_{i}$ is a un-observed fixed person effect, $\pi_{s t}$ is a vector of state $\times$ year fixed effects and $\nu_{i s t}$ is an error term. The person effect $\alpha_{i}$ is analogous to the fixed county effect $\delta_{c}$ in the county-level turnout analysis, and captures the fact that the outcomes are partly determined by unobserved individual traits that also affect the likelihood of being employed at any point in time. Failure to account for this would tend to bias estimates of

\footnotetext{
${ }^{18}$ See the Theory Appendix for a simple formalization of an argument linking labor market activity, information and voting.
} 
the parameter $\lambda_{1}$. The natural way to account for these latent confounds would be to apply fixed effects methods to (6), which requires that the data source from which we obtain individual level data on labor supply, information, media exposure and voting have a longitudinal feature, in which the same individual is interviewed across successive election years and asked about the relevant variables in both years.

We use data from the American National Election Studies (ANES) Cumulative Data File (American National Election Studies 2011). The ANES is primarily a repeated cross-sectional survey, conducted in 1948 and every other year since 1952. ANES respondents are interviewed twice during presidential election years, once in the weeks prior to the election and again in the weeks following the election. In non-presidential election years, individuals are only interviewed once following the election. In addition to some demographic information, the ANES reports respondents' turnout (based on self-reports of voting), employment status, state of residence, and provides measures of voters' political information and their use of various forms of media.

In various years (1956-1960, 1972-1976, and 1992-1996), the ANES has a rarely-used panel component, in which the same people were interviewed across successive presidential years. During these years the survey provides information about both voters' level of political information and their exposure to media. In presidential election years since 1968, the ANES includes a variable which reflects the ANES interviewer's assessment of the respondent's general level of information about politics and public affairs, based on the respondent's answers to various questions over the course of the survey interview. This measure is collected in both the pre-election and post-election interviews. The interviewer codes his assessment of the respondent's level of political information on a five point scale ranging from "very high" to "very low". We define a respondent as being informed if the interviewer codes their information level as "very high" or "fairly high".19

The survey also reports a measure of a respondent's exposure to campaign information from multiple media sources. This measure is available in all presidential elections years during the postelection interview from 1952 to 1996, except for 1988, and a handful of non-presidential election years. This Media Exposure Index summarizes how many of four different types of media (t.v., radio, magazines, newspapers) respondents report having gotten information from about the recently completed election. We use observations for this index for which there are valid responses for each

\footnotetext{
${ }^{19}$ We have no more information on what each interviewer uses to come up with this rating, beyond his or her judgement after speaking going through the entire survey with the respondent.
} 
of the four discrete elements from which the index is constructed. We define the respondent as being informed if they accessed three or more of these media sources.

Table 7 presents estimates of the effect of employment on information and media exposure from individual ANES data. ${ }^{20}$ Column (1) presents results from pooled cross-section models across all available years. Column (2) presents pooled cross-section estimates, but only for the ANES panel sample. Column (3) shows the results from a difference model - estimated, of course, on the panel sample. ${ }^{21}$ We find that in the pooled cross-section, being employed is very strongly positively correlated with being thought by the independent interviewer to be a politically informed person, and with being rated highly on the Media Exposure index. For the indicator of being politically informed, the pooled result is significant in both the full sample and in the panel sample. For the media exposure measure, the pooled point estimate is significant in the full sample and large but not statistically different from zero in the panel sample. These results seem inconsistent with the argument about information exposure, but they are undoubtedly contaminated by the presence of unobserved person effects, $\alpha_{i}$, which likely impart positive bias to the estimates.

The difference-estimator results shown in column (3) differ sharply from the naive pooled estimates. Once person-specific fixed effects are accounted for, we find that whether a person is informed about politics and his level of media exposure are both negatively related to his being employed, precisely as the argument linking leisure to information exposure predicts. ${ }^{22}$ The results suggest that employment and the two measures of information are positively associated with unobserved person-specific factors. The estimated effects for gaining employment on being informed and for having a high level of media exposure are -.097 and -.077, respectively. These are both relatively large compared to the means of the two variables of 0.39 and 0.49 . These results provide

\footnotetext{
${ }^{20}$ The media exposure index is only asked in a post-election survey, so there is an unavoidable slight discrepancy between the timing of the information questions and the labor supply measures.

${ }^{21}$ Comparisons of sample sizes between the interviewer's assessment of respondent information (Panel A) and the Media Exposure Index (Panel B) must account for the higher rate of missing data for the Media Exposure Index arising from three sources. First, the media measures are based on respondent answers to four items while the interviewers provide an information assessment. Second, the ANES used multiple survey forms in some years such that not all respondents were asked the same questions in a given year. Roughly half of respondents were not asked the media questions in 1972 and roughly one-tenth were not asked in 1992. Third, since 1988 the newspaper media question is only asked for those who first respond that they have read a newspaper during the past. As an example of the impact on the sample sizes, the number of respondents providing valid observations in adjacent panel years for column (3) is 672 in 1972-76 and 574 in 1992-96 in Panel A and 644 in 1956-60, 316 in 1972-76, and 348 in $1992-96$ in Panel B.

${ }^{22}$ This result is consistent with recent work on time use and labor supply. For example Krueger and Mueller (2008) find that television viewing constitutes fully one third of the "awake" time of the unemployed in the United States. They further show that, compared to employed persons, the unemployed spend nearly twice as much time viewing TV during the weekday (201 mins vs. 106 mins per day) and about $30 \%$ more on weekends (209 mins vs. 162 mins). Presuming that TV viewing exposes people to more political information, this finding is consistent with our results.
} 
evidence for the mechanism that we have argued best explains the various county-level turnout results. ${ }^{23}$

\section{Discussion and Conclusion}

Using county-level data that we have assembled for elections between 1969 and 2000, and employing a variety of OLS and TSLS models, we find that increases in local per capita earnings and log employment per adult reduce voter turnout in gubernatorial, congressional, senatorial and state legislative elections, but have no statistically significant effect on turnout in presidential contests. We also study the difference in voting between different pairs of elections appearing on the same ballot. For these elections, the shoe-leather, or logistical, costs that must be incurred to vote in one election is the same as the cost of voting on both. We find that, across different pairs of elections, the share of people voting in the one that traditionally receives higher votes but not in the other election on the same ballot increases with greater labor market activity in the county. Our findings are robust to a number of extensions and robustness tests.

We argue that an explanation for this broad set of results may be forthcoming from the class of voting models which argue that poor information reduces participation. If the methods by which people acquire political information are complementary with leisure time, then increased labor market activity should leave them less informed about political matters and thus, in general, less likely to vote. If the size of this effect differs across elections, as might be the case if reduced leisure has only a modest effect on information acquisition in more prominent or "note-worthy" elections, a model of limited information and voting might could also explain both the zero effect we estimate for presidential contests and the roll-off results. Using fixed effects methods applied to individual ANES data, we find that, indeed, changes in labor supply are systematically negatively related to changes in media exposure and an objective measure of voters' political knowledge.

Beyond contributing to the literature studying turnout per se, our results have implications for

\footnotetext{
${ }^{23}$ Unfortunately, the information available in the ANES about voting prevents us from conducting an analysis of voting using the individual data that corresponds to the specification in Table 7 . Because of well-known problem of unreliable voting self-reports (see Katz and Katz 2000), the ANES has conducted a validation study, intended in part to measure the degree of mis-reporting of voting in the survey, which partially spans the panel years. However, the validation information only verifies whether someone went to the polls at all; the data cannot be used to ascertain whether someone who reports voting for both, say, the presidential and House of Representative elections actually voted in only one of these elections when he went into the voting booth. Indeed, the survey does not consistently inquire about voting in certain types of elections in the panel sample at all, including gubernatorial voting. This is an important limitation, since a key result in our paper is that the effect of labor market activity on turnout differs across election types.
} 
other active areas of research. One of these is the burgeoning literature in economics and political economy on information. Various observational studies find that citizens with more political information are more likely to vote (Palfrey and Poole 1987; Wattenberg et al. 2000; Coupe and Noury 2004), as do laboratory studies in which research subjects are assigned information (Battaglini, Morton, and Palfey 2010). We have already noted the large number of recent papers studying how changes in the presence of media affect voting, presumably through an effect on voters' information. Our results suggest that voting might be affected by not only by how much information is available, but by how economic factors like leisure affect people capacity to access political information. This issue has received little previous attention in the literature. Nor have closely related issues, such as the possibility that political actors may strategically adjust the dissemination of political information so as to exploit predictable variation in people's exposure to information arising from changes in labor market activity.

The most important implications of our work may be for the literature studying how variation in economic outcomes affects which candidate wins various elections. One set of issues raised by our analysis concerns data and empirical specifications. As noted earlier, the "economic voting" literature tries to determine whether voters reward or punish politicians for changes in economic circumstances by relating measures of aggregate economic outcomes to the share of votes received by a politician. Various papers in this area have estimated a positive coefficient between the incumbent's vote share and measures of economic performance, but these results have typically relied upon aggregate state-level data. Yet, our analysis shows that, at least for turnout, using county-level data and the specifications they permit, produces materially different results that those forthcoming from analysis with more aggregate data. Whether something similar would be true for the study of vote share is not clear, but is an obvious issue for future economic voting work raised by our analysis.

How existing and future vote share results are interpreted should also be affected by our results. A positive relationship between the share of votes received by the incumbent and measures of economic performance has usually been taken to be evidence of a change in the voters' sentiments about the candidates. Further, this change in sentiment is regarded as irrational, since rational voters should neither punish nor reward politicians for aggregate economic outcomes over which they have limited, if any, influence. Our findings in this paper suggest that a positive relationship between economic activity and the vote share might arise even if economic activity does not people's 
views about a candidate's quality, but change instead the type or number of people who rationally choose to vote because their greater attention to market-related activity leaves them less informed about political matters. Since existing work on the vote share has not studied turnout directly, it is not clear how important this second mechanism is. Our results, which study different types of elections, suggest that it might not be especially large for presidential contests, where turnout seems impervious to labor market activity, but might be much more important for other types of elections. An important future challenge for the economic voting literature will thus be to formally incorporate the turnout decision into both theoretical and empirical analysis of the vote share and of how economic performance affects who wins elections. 


\section{References}

Acemoglu, Daron, Amy Finkelstein and Matthew J. Notowidigdo 2009. Income and Health Spending: Evidence from Oil Price Shocks. NBER Working Paper

Achen, Christopher H. 2005. Bayesian Voters and Their Turnout Decisions: Unifying the Behavioral Literature. Unpublished manuscript.

Ansolabehere, Stephen, Shanto Iyengar, Adam Simon and Nicholas Valentino. 1994. Does Attack Advertising Demobilize the Electorate. American Political Science Review. 88(4): 829-838.

Ashenfelter, Orley and Stanley Kelley, Jr. 1975. Determinants of Participation in Presidential Elections. Journal of Law and Economics, 18:695-733.

Ashworth, Scott. 2011. Targeted Campaigns with Ambiguity Averse Voters. Unpublished manuscript.

Black, Dan, Kermit Daniel and Seth Sanders. 2002. The Impact of Economic Conditions on Participation in Disability Programs: Evidence from the Coal Boom and Bust. American Economic Review 92(1), March: pp 27-50.

Blais, Andre and Agnieszka Dobrznska. 1998. Turnout in Electoral Democracies. European Journal of Political Research, 33:239-261.

Bogue, Donald J. 1951. State Economic Areas. Washington, DC: U.S. Government Printing Office.

Bound, John, Charles C. Brown, and Nancy Mathiowetz. 2001. Measurement Error in Survey Data. In Handbook of Econometric, edited by E.E. Learner and J.J. Heckman. New York: North Holland Publishing Pp. 3705-3843.

Brody, Richard A. and Paul M. Sniderman. 1977. From Life Space to Polling Place: The Relevance of Personal Concerns for Voting Behavior. British Journal of Political Science 7 (March): 337-360.

Brunner, Eric, Stephen L. Ross and Ebonya Washington. 2011. Economics and Policy Preferences: Causal Evidence of the Impact of Economic Conditions on Support for Redistribution and Other Ballot Proposals. Review of Economics and Statistics. 93(3): 888-906.

Bullock, Chares S. III and Richard E. Dunn. 1996. Election Roll-Off: A Test of Three Explanations. Urban Affairs Review 32 (September): 71-86.

Degan, Arianna and Antonio Merlo. 2011. A Structural Model of Turnout and Voting in Multiple Elections. Journal of the European Economic Association, 9(2): 209-245.

Dehejia, Rajeev and Adriana Lleras-Muney. 2004. Booms, Bust, and Babies' Health. Quarterly Journal of Economics, 119(3): 1091-1130.

Dellvigna, Stefano and Ethan Kaplan. 2007. The Fox News Effect: Media Bias and Voting. Quarterly Journal of Economics 122 (August): 1187-1234. 
Downs, Anthony. 1957. An Economic Theory of Democracy, New York: Harper and Row.

Feddersen, Timothy and Wolfgang Pesendorfer. 1996. The Swing Voter's Curse. American Economic Review, 86(3): 404-24.

Ferreira, Francisco H. G. and Norbert Schady. 2009. Aggregate Economic Shocks, Child Schooling and Child Health. World Bank Research Observer, 24(2): 147-181.

Gentzkow, Matthew. 2006. Television and Voter Turnout. Quarterly Journal of Economics 121 (August): 931-72.

Gentzkow, Matthew, Jesse M. Shapiro and Michael Sinkinson. 2009. The Effect of Newspaper Entry and Exit on Electoral Politics American Economic Review, 101 (December 2011): 29803018.

Ghirardato, Paolo and Jonathan N. Katz. 2002. Indecision Theory: Quality of Information and Voting Behavior. Unpublished manuscript.

Hibbs, Douglass Hibbs Jr. (2005). Voting and the Macroeconomy, in The Oxford Handbook of Political Economy, Barry R. Weingast and Donald Wittman, eds. Oxford University Press.

Katz, Jonathan N. and Gabriel Katz. Forthcoming. Correcting for Survey Misreports using Auxiliary Information with an Application to Estimating Turnout. American Journal of Political Science.

Kinder, Donald R. and D. Roderick Kiewiet. 1981. Sociotropic Politics: The American Case. British Journal of Political Science 11(2): 129-161.

Kirchgassner Gerard and Anne Meyer Zu Himmern. 1997. Expected Closeness and Turnout: An Empirical Analysis for the German General Elections 1983-1994. Public Choice, 91: 3-25.

Krueger, Alan and Andreas Mueller. 2008. The Lot of the Unemployed: A Time Use Perspective. IZA Discussion Paper, \# 3490.

Lassen, David, 2005. The Effect of Information on Voter Turnout: Evidence from a Natural Experiment. American Journal of Political Science, 49(1): 103-18.

Lau, Richard R. 1985. Two Explanations for Negativity Effects in Political Behavior. American Journal of Political Science, 29: 119-38.

Lewis-Beck, Michael S. and Mary Stegmaier. 2000. Economic Determinants of Electoral Outcomes. Annual Review of Political Science, 3:183-219.

Lijphart, Arend. 1997. Unequal participation: Democracys unresolved dilemma. American Political Science Review 91 (1): 114.

Matsusaka, John G. 1995. Explaining Voter Turnout Patterns: An Information Theory. Public Choice, 84(1-2) (July): 91-117. 
Matsusaka, John G. and Filip Palda. 1999. Voter Turnout: How Much Can We Explain? Public Choice, 98:431-46.

Merlo, Antonio. 2006. Whither Political Economy? Theories, Facts and Issues. In Advances in Economics and Econometrics: Theory and Applications, Ninth World Congress, Volume I, ed. Richard Blundell, Whitney K. Newey and Torsten Persson: Cambridge University Press, pp. 381421.

Mueller, Dennis C. 2003. Public Choice III. Cambridge: Cambridge University Press.

Mueller, Dennis C. and Thomas Stratmann. 2003. The Economic Effects of Democratic Participation. Journal of Public Economics. 87(9-10): 2129-2155.

Nordhaus, William. 1975. The Political Business Cycle. Review of Economic Studies. 42:169-190. Palfrey, Thomas R. and Howard Rosenthal. 1983. Voter Participation and Strategic Uncertainty, American Political Science Review, 79, 62-78.

Putnam, Robert D. 2000. Bowling Alone: The Collapse and Revival of American Community. New York: Simon and Schuster.

Radcliff, Benjamin. 1992. The Welfare State, Turnout and the Economy: A Comparative Analysis. American Political Science Review, June, 82:2: 444-454.

Rosenstone, Steven J. 1982. Economic Adversity and Voter Turnout. American Journal of Political Science, 26(1) (February): 25-46.

Ruhm, Christopher J. 2000. Are Recessions Good for Your Health? Quarterly Journal of Economics, 115(2): 617-650.

American National Election Studies. American National Election Studies (ANES) Cumulative Data File, 1948-2008. ICPSR08475-v14. Ann Arbor, MI: Inter-university Consortium for Political and Social Research [distributor], 2011-12-05.

Scholzman, Kay Lehman and Sidney Verba. 1979. Injury to Insult. Cambridge: Harvard University Press.

Snyder, James M. and David Stromberg. 2010. Press Coverage and Political Accountability. Journal of Political Economy, Vol 118(2): 355-408.

Southwell, Patricia L. 1988. The Mobilization Hypothesis and Voter Turnout in Congressional Elections. Western Political Quarterly, 41(2): 173-88.

Stigler, George J. 1973. Mirco Politics and Macro-Economics: General Economic Conditions and National Elections. The American Economic Review, 63 (2) (May): 160-67.

Stigler, George J. 1975. The Effects of Economic Policies on Votes for the Presidency: Some Evidence from Recent Elections: Comment. Journal of Law and Economics, 18 (3) (December):801-02. 
Stromberg, David. 2004. Radio Impact on Public Spending. Quarterly Journal of Economics, CXIX (2004): 189-221.

Wattenberg, Martin, Ian McAllister, and Anthony Salvanto. 2000. How Voting is Like an SAT Test: An Analysis of American Voter Rolloff. American Politics Quarterly, 28(2): 234-50.

Wolfers, Justin. 2002. Are Voters Rational? Evidence from Gubernatorial Elections. Stanford GSB Research Paper no. 1730.

Wolfinger, Ray and Steven Rosenstone. 1980. Who Votes? New Haven: Yale University Press.

$\mathrm{Xu}$, Xing and Robert Kaestner. 2010. The business cycle and health behaviors (Vol. Working Paper No. 15737): National Bureau of Economic Research Cambridge, Mass., USA. 
A. Real Price of Oil, Natural Gas, and Coal
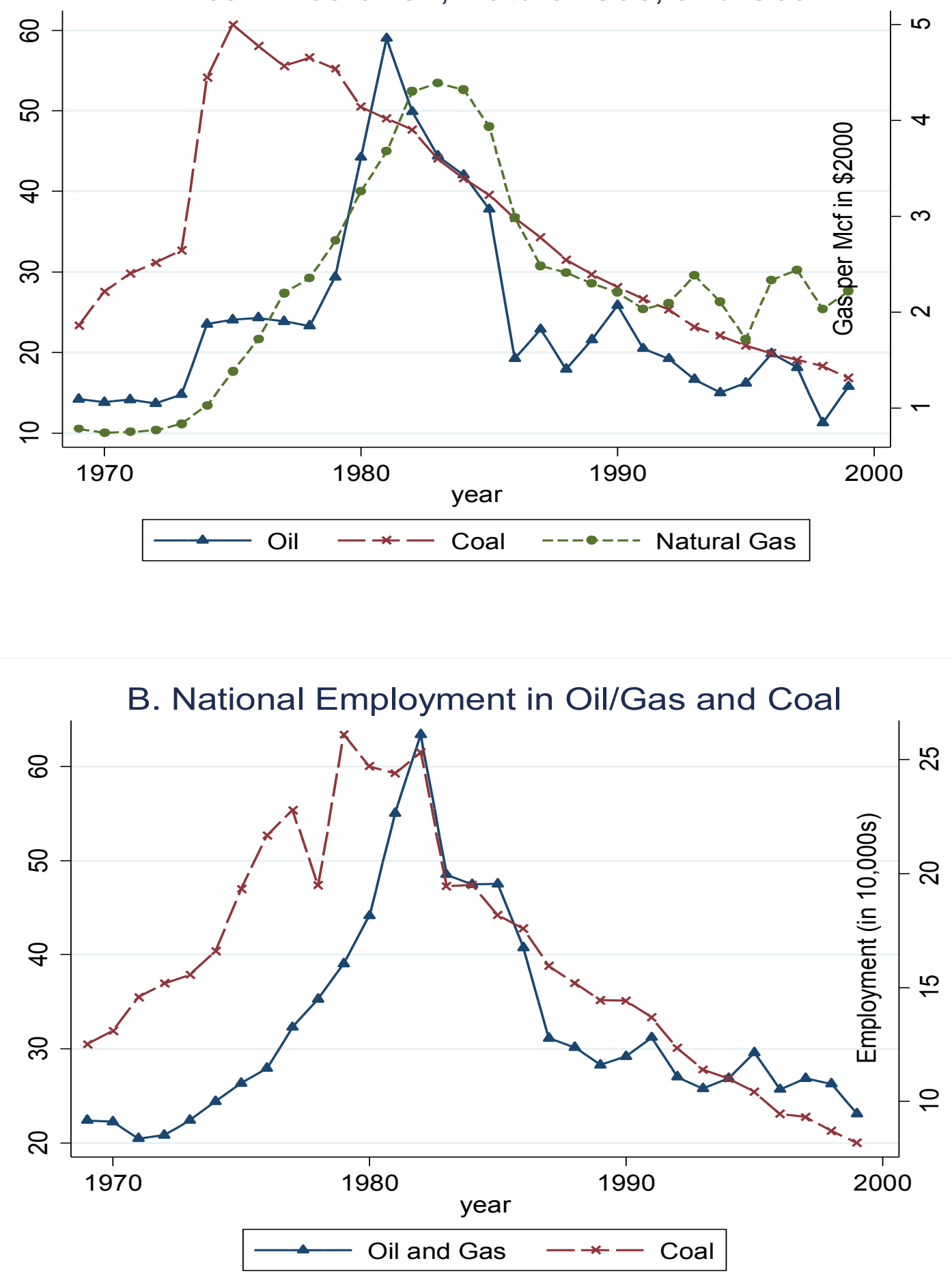

Figure 1: Effect of Energy Supply Shocks on Changes in Price and National Employment in Oil/Gas and Coal. 
Table 1. Mean Turnout from 1969-2000, by Election Type, Across All U.S. Counties

(Standard Deviations in Parentheses).

\begin{tabular}{cccccc}
\multicolumn{2}{c}{ "State-Wide" Elections } & & \multicolumn{2}{c}{ "Local" Elections } \\
\cline { 1 - 2 } President & Governor & Senator & & U.S. Congress & State Legislator \\
$(4-$-Year Cycle $)$ & $(4-Y e a r$ Cycle $)$ & $(6-$ Year Cycle $)$ & & $(2-$ Year Cycle $)$ & $(2-$ Year Cycle $)$
\end{tabular}

\section{Mean Turnout}

All Years

0.548

$(.095)$

0.427

$(.109)$

0.467

(.115)

0.462

(.128)

0.445

Presidential Years

0.572

(.090)

0.530

(.096)

0.513

(.109)

(.126)

Non-Presidential Years

\subsection{5}

(.094)

0.405

(.097)

0.387

(.118)

0.506

376

$\begin{array}{cc}346 & 495 \\ 74 & 248 \\ 0.21 & 0.50\end{array}$

Number of elections in Presidential years

Percent of elections in Presidential years

Data drawn from multiple sources on aggregate voting data. See Data Appendix for details.

Sample means and standard deviations are weighted by number of adults. 
Table 2. The Effect of Local Economic Performance on Voter Participation: County-Level Regressions for All U.S. Counties for Gubernatorial, Senate and Presidential Elections from 1969-2000.

OLS Estimates of Pooled and First-Difference (Change Since Last Election) Models.

\section{Local Labor Market}

Measure

(1) Log per capita earnings (a)

Pooled

\section{Governor}

(b)

(b)
Difference$$
.031
$$

$$
-.013
$$

$\begin{array}{ll}.040 & -.060 \\ (.009) & (.029)\end{array}$

$$
\begin{aligned}
& -.060 \\
& (.029)
\end{aligned}
$$

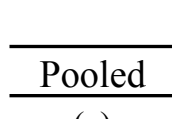

(a)
Difference

(b) (c)

(c)

.038

(.006)

$$
-.014
$$

(.013)

$$
\begin{gathered}
.001 \\
(.005)
\end{gathered}
$$

$$
\begin{gathered}
.048 \\
(.010)
\end{gathered}
$$

$$
-.001
$$$$
\text { (.008) }
$$

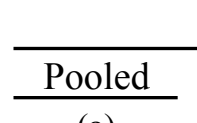

(a)

President

Difference

(b) (c)

(c)

Year Effects

State Effects

State* Year Fixed Effects

Population Share Controls?

$$
\text { Yes }
$$

Yes

No

Yes

No

No

No

No

Yes

Yes$$
\text { Yes }
$$$$
\text { Yes }
$$

$$
\text { Yes }
$$

Yes

$$
\text { No }
$$$$
\text { Yes }
$$

$$
\text { Yes }
$$

No

$$
\text { No }
$$$$
\text { Yes }
$$

31324

25012

19872

19872

22992

Each point estimate in the table represents results from a different regression.

Standard errors account for arbitrary forms of clustering within states.

All regressions control for Change Since Last Election in: log total population; percentage female adults; percentage Black adults, percentage "other" race;

percentage population aged 30s, 40s, 50s, 60s, 70 and up

All regressions are weighted by the number of adults. 
Table 3. OLS Estimates of Effect Oil and Coal Supply Shocks on Change Since Last Election in County Labor Market Outcomes and Change in County Voter Participation for Gubernatorial, Senate and Presidential Elections from 1969-1990.

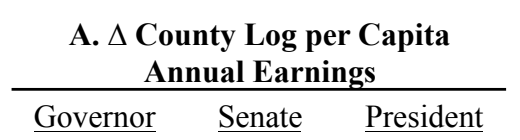

B. $\Delta$ County Log Employment per

B. $\Delta$ County Log Em
Adult

Governor Senate President

C. $\Delta$ Voter Turnout

Governor Senate $\underline{\text { President }}$

\section{Oil/Coal Supply Shock:}

( $\Delta \log$ National Coal Employment) X I(Medium_Coal_1974)

( $\Delta \log$ National Coal Employment) X I(Large_Coal_1974)

( $\Delta$ log National Oil Employment) X I(Medium_Oil_1974)

( $\Delta$ log National Oil Employment) X I(Large_Oil_1974)

\begin{tabular}{ccccccccc}
.108 & .182 & .205 & .008 & .039 & .067 & -.014 & -.011 & .018 \\
$(.029)$ & $(.035)$ & $(.045)$ & $(.024)$ & $(.016)$ & $(.015)$ & $(.010)$ & $(.004)$ & $(.008)$ \\
& & & & & & & & \\
.281 & .324 & .340 & .114 & .136 & .152 & -.022 & -.011 & .004 \\
$(.073)$ & $(.072)$ & $(.117)$ & $(.014)$ & $(.012)$ & $(.020)$ & $(.011)$ & $(.017)$ & $(.006)$ \\
& & & & & & & \\
.041 & .023 & .029 & .024 & .008 & .007 & -.006 & .003 & -.005 \\
$(.011)$ & $(.011)$ & $(.020)$ & $(.007)$ & $(.008)$ & $(.018)$ & $(.004)$ & $(.007)$ & $(.003)$ \\
& & & & & & & \\
.153 & .115 & .120 & .060 & .048 & .051 & -.035 & -.012 & -.0002 \\
$(.028)$ & $(.025)$ & $(.033)$ & $(.014)$ & $(.015)$ & $(.022)$ & $(.005)$ & $(.007)$ & $(.006)$ \\
& & & & & & & & \\
Yes & Yes & Yes & Yes & Yes & Yes & Yes & Yes & Yes \\
13.4 & 11.0 & 10.9 & 19.5 & 32.6 & 17.4 & & & \\
4751 & 6014 & 4412 & 4751 & 6014 & 4412 & 4751 & 6014 & 4412 \\
\hline
\end{tabular}

State*Year Fixed Effects

F-Stat on Oil/Coal Instrument

\section{Observations}

4751

Each column in the table represents results from a different regression.

Standard errors account for arbitrary forms of clustering within states.

Counties are "medium" if share of employment in oil/coal at least 5 percent but less than 20 percent; "large" if share equals or exceeds 20 percent

All regressions control for Change Since Last Election in: log total population; percentage female adults; percentage Black adults, percentage "other" race;

percentage population aged $30 \mathrm{~s}, 40 \mathrm{~s}, 50 \mathrm{~s}, 60 \mathrm{~s}, 70$ and up

All regressions are weighted by the number of adults. 
Table 4. OLS and TSLS Estimates of Effect of Change in County-Level Labor Market Outcomes on Change in Voter Turnout. Gubernatorial, Senate, and Presidential Elections from 1969-1990 in "Oil" and "Coal" States.

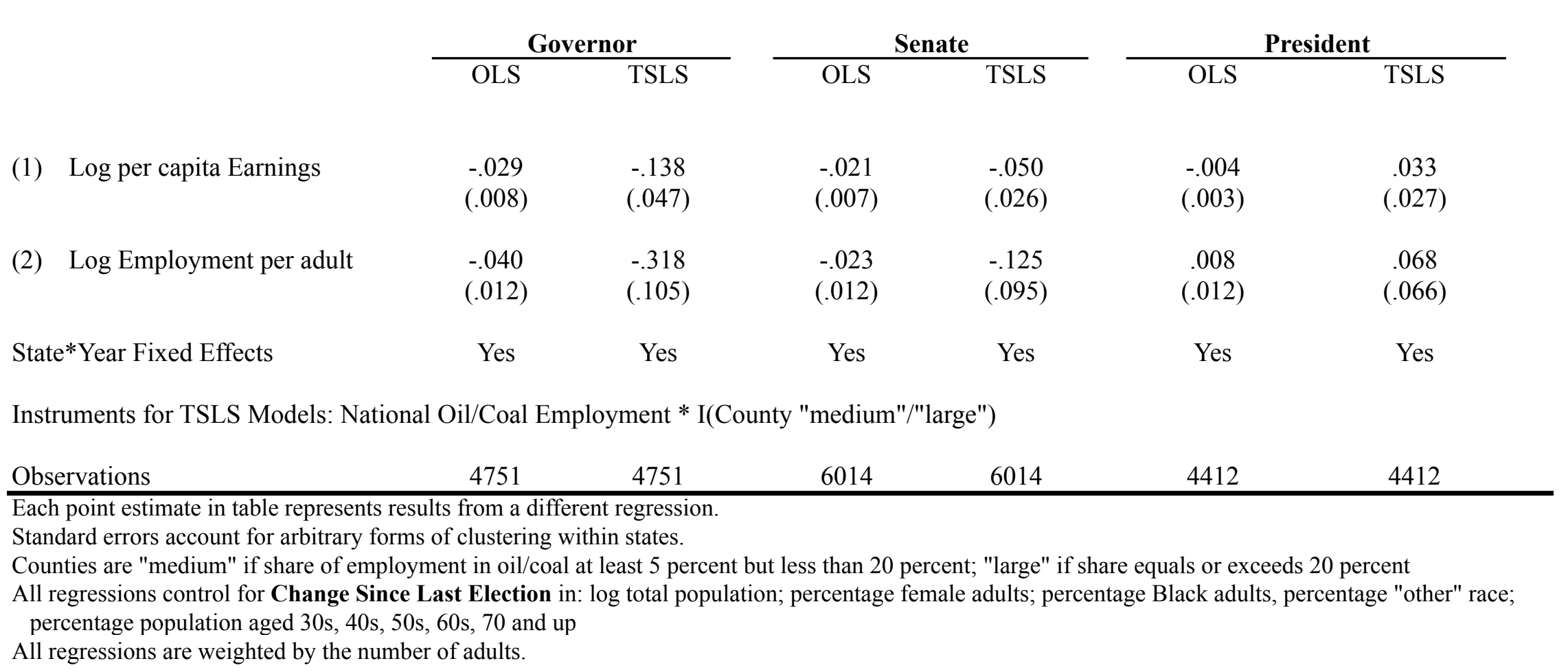


Table 5. OLS, Difference and TSLS County-Level Estimates of the Effect of Local Economic Economic Activity on Voter Turnout in Elections for U.S Congress and State Legislatures (Standard Errors in Parentheses).

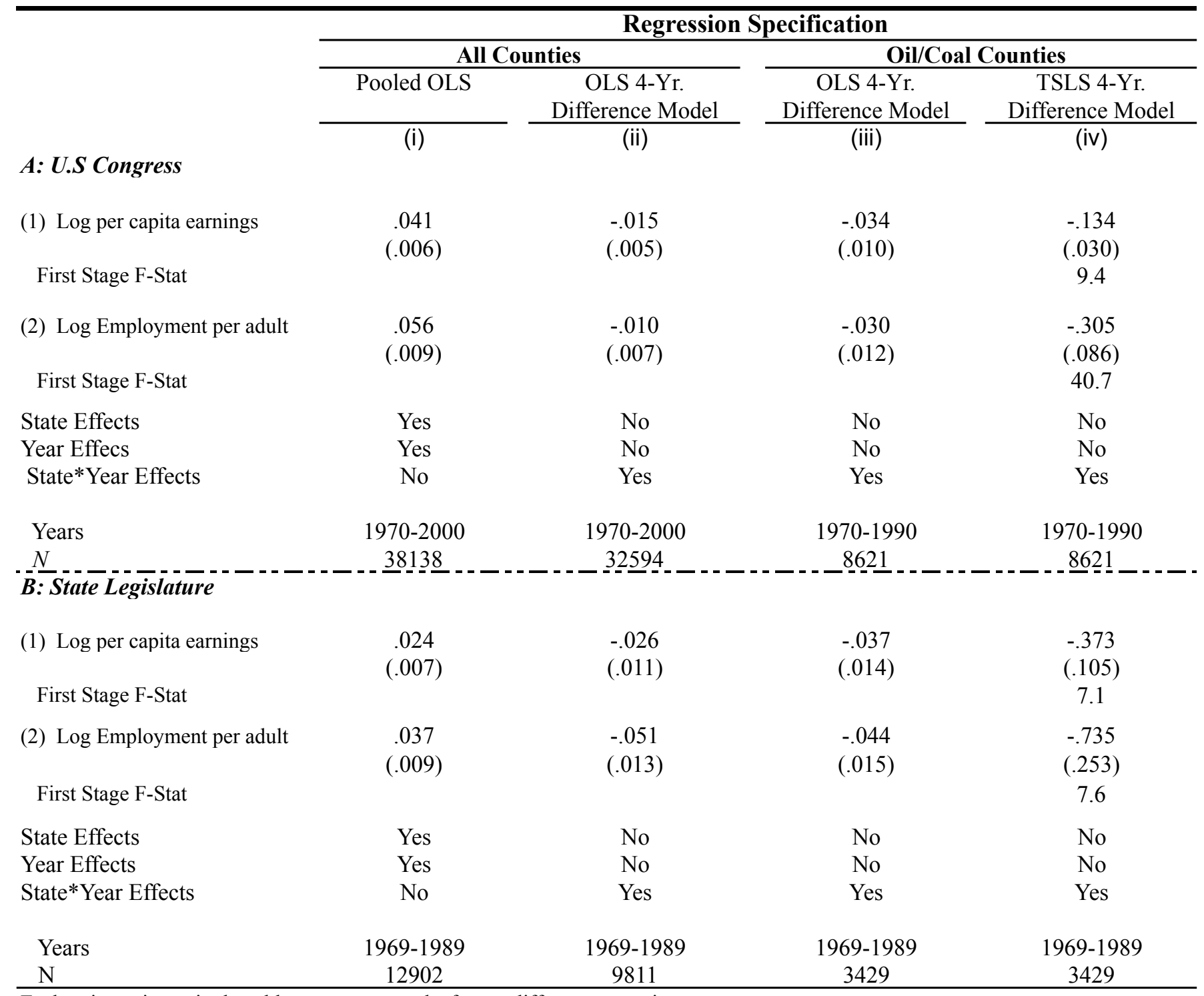

Each point estimate in the table represents results from a different regression.

All regressions are weighted by the number of adults.

See Data Appendix for further details about sample. 
Table 6. OLS Estimates of Effect of Labor Market Activity of Change in Share of County Voting in One Election but Not in Another on Same Ballot.

Election Pairs Over Which Difference in Voting Measured

\begin{tabular}{|c|c|c|c|c|c|c|c|c|}
\hline & & & & & & & & \\
\hline & Pres. - Cong. & Pres. - State & Gov. - State & Sen. - State & Pres. - Gov. & Pres. - Sen. & Gov. - Cong. & Sen. - Cong. \\
\hline $\begin{array}{c}\text { Mean Roll-Off } \\
\text { (Std. Dev) }\end{array}$ & $\begin{array}{r}0.037 \\
-(0.040)\end{array}$ & $\begin{array}{c}0.065 \\
(0.048) \\
\end{array}$ & $\begin{array}{r}0.042 \\
-(0.034)\end{array}$ & $\begin{array}{c}0.044 \\
(0.041)\end{array}$ & $\begin{array}{c}0.003 \\
(0.011)\end{array}$ & $\begin{array}{c}0.017 \\
(0.022) \\
\end{array}$ & $\begin{array}{c}0.024 \\
(0.041)\end{array}$ & $\begin{array}{c}0.020 \\
-(0.042)\end{array}$ \\
\hline $\begin{array}{l}\text { og per capita } \\
\text { arnings }\end{array}$ & $\begin{array}{l}.012 \\
(.004)\end{array}$ & $\begin{array}{l}.019 \\
(.016)\end{array}$ & $\begin{array}{l}.005 \\
(.009)\end{array}$ & $\begin{array}{l}.003 \\
(.010)\end{array}$ & $\begin{array}{l}.003 \\
(.004)\end{array}$ & $\begin{array}{l}.010 \\
(.004)\end{array}$ & $\begin{array}{l}.001 \\
(.006)\end{array}$ & $\begin{array}{l}.003 \\
(.006)\end{array}$ \\
\hline $\begin{array}{l}\text { og Employment } \\
\text { ser adult }\end{array}$ & $\begin{array}{c}.024 \\
(.010)\end{array}$ & $\begin{array}{l}.036 \\
(.020)\end{array}$ & $\begin{array}{l}.027 \\
(.016)\end{array}$ & $\begin{array}{l}.016 \\
(.009)\end{array}$ & $\begin{array}{l}-.001 \\
(.006)\end{array}$ & $\begin{array}{l}.005 \\
(.007)\end{array}$ & $\begin{array}{l}-.006 \\
(.013)\end{array}$ & $\begin{array}{l}-.005 \\
(.011)\end{array}$ \\
\hline *Year Effects & Yes & Yes & Yes & Yes & Yes & Yes & Yes & Yes \\
\hline $\mathrm{N}$ & 19056 & 5033 & 4431 & 5381 & 3894 & 6700 & 12234 & 18019 \\
\hline
\end{tabular}

Each point estimate in the table represents results from a different regression.

Pres., Cong., State, Gov, and Sen denote, in turn elections for: President, U.S. Congress, State Legislature, Governor and Senator.

All regressions are weighted by the number of adults.

See Data Appendix for further details about sample. 
Table 7. OLS and Within Individual-Level Estimates of Effect of Being Employed on Alternative Measures of Political Information and Media Exposure in the American National Election Study.

\begin{tabular}{|c|c|c|c|}
\hline & (1) & (2) & \multirow{3}{*}{$\begin{array}{c}(3) \\
\text { Within Estimator } \\
\underline{\text { Panel Sample }}\end{array}$} \\
\hline & \multicolumn{2}{|c|}{ Pooled OLS } & \\
\hline & Full Sample & Panel Sample & \\
\hline A: & \multicolumn{3}{|c|}{$\begin{array}{l}\text { Interviewer reports of Respondent's general level of information about } \\
\text { politics/public affairs seemed "very high" or "fairly high"? }\end{array}$} \\
\hline Mean of Dependent Variable & 0.39 & 0.45 & 0.45 \\
\hline Respondent Employed? & $\begin{array}{l}.068 \\
(.008)\end{array}$ & $\begin{array}{l}.050 \\
(.028)\end{array}$ & $\begin{array}{l}-.097 \\
(.039)\end{array}$ \\
\hline Years and Sample from ANES & $\begin{array}{l}\text { Presidential Election } \\
\text { Years 1968-2004 }\end{array}$ & $\begin{array}{r}1972-1976, \\
1992-1996\end{array}$ & $\begin{array}{r}1972-1976, \\
1992-1996\end{array}$ \\
\hline $\begin{array}{l}\text { Number of Observations } \\
\text { Number of Unique Respondents }\end{array}$ & 19368 & 2492 & $\begin{array}{l}2492 \\
1246\end{array}$ \\
\hline
\end{tabular}

B: Mean of Dependent Variable Respondent Employed?

Years and Sample from ANES

Number of Observations

Number of Unique Respondents

ANES Media Exposure Index "high": Respondent exposed to political campaign on 3 or more of tv, radio, magazine or newspaper?

0.49

.031

(.010)
Presidential Election Years 1952-2004
16882
1956-1960, 1972-1976, 1992-1996 2616

0.51

.019

(.029)
0.51

$-.077$

(.044)
1956-1960, 1972-1976, 1992-1996

2616 1308

All Regressions Include Constant Term, State*Year Fixed Effects, Age, Age-Squared.

Pooled OLS regressions also include dummy variables for whether Respondent Male.

Data from Multiple Years of American National Elections Study. See text for details.

All regressions account for clustering on the household level.

For panel regressions, we use sample weights for observations in year 1960 for both 1956 and 1960, weights in 1976 for 1972 and 1976, and weights in 1996 for 1992 and 1996. 


\section{Data Appendix}

\section{Matching Across Data Sources}

Matching the data from the various sources was facilitated by the use of county FIPS codes. Merging was based on the modified FIPS codes used by the REIS. These county FIPS codes are generally the same as the standard FIPS codes with the exception that many independent cities in Virginia are merged with neighboring counties to create new counties. Since most data sources contain separate observations for these independent cities, these observations are first summarized according to the definitions of these new counties and then merged by the REIS FIPS codes. (Independent cities in Maryland, Missouri, and Nevada appear as separate observations in the REIS data and thus require no further adjustment.)

The voting data available from ICPSR uses the ICPSR county codes as opposed to the FIPS county codes. A bridge file between FIPS and ICPSR county codes is used to connect the ICPSR files with the remaining data sources.

To address a small number of counties which are involved in either a merge or a split during our sample period, we only use observations for these counties from the after the merge or split. Counties which split during the sample period are Yuma, AZ (creating La Paz, AZ in 1983) and Valencia, NM (forming Cibola, NM in 1981). Counties which merged during this period are Washbaugh, SD and Jackson, SD in 1976 as well as Nansemond, VA and Suffolk City, VA. In addition, a few cities in Virginia annexed parts of surrounding counties including Roanoke City, VA (annexed part of Roanoke county in 1975), Petersburg City, VA (annexed parts of Dinwiddie, VA and Prince George, VA in 1972), and Lynchburg City, VA (annexed parts of Bedford, VA and Campbell,VA in 1975).

\section{County-Level Voting Data}

We use county-level voting totals found from three primary sources. For 1969-1990, we use data from ICPSR study no. 13 General Election Data for the United States, 1950-1990. For subsequent years, Presidential, Senatorial, and Gubernatorial returns were obtained from the CQ Press Voting and Elections Collection while the Congressional returns were obtained from Election Data Services, Inc. The Congressional data is limited to Presidential years, and does not include the years 1994 and 1998.

We made a number of adjustments to these voting returns to account for incomplete and apparent incorrect data. First, since the ICPSR data are available for even-numbered years only prior 1980, gubernatorial elections which occur in odd-numbered year are, for the most part, not found in the ICPSR data. Kentucky, Louisiana, Mississippi, New Jersey, and Virginia have odd year governor elections. These data were obtained from the CQ Press Voting and Elections Collection. However, for some odd-year elections prior to 1972, the election results are incorrectly entered into an adjacent even year. These observations were moved to the appropriate years.

Second, in some instances all of the data for a single state for a given election during the period in which the ICPSR data is the primary source was replaced with data from CQ either due to missing data or numerous suspicious values. A list of these elections is available from the authors.

A small fraction of individual counties in each year have data that apparent most likely because of incorrect coding. In some instances, these errors appear to be due to a switch in values for observations which appear consecutively in the alphabetized county list. In other instances, the data were incorrectly entered. A list of these counties and elections which have 
individual election problems that were corrected is available from the authors. In addition, for Congressional election data, we investigated the individual county returns whenever the overall total number of votes recorded for a state in a given year did not match the total number found on the Election Information webpage for the Clerk of the House of Representatives (http://clerk.house.gov/member_info/electionInfo/index.html).

We also drop observations due to a lack reported votes on election data. We do not use Louisiana in our analysis since elections in the state during this period except Presidential elections are subject to a non-partisan primary in which all candidates from both parties are on the same primary ballot. A run-off election is held between the top two vote getters, regardless of party, unless one of the candidates receives at least $50 \%$ of the vote in the primary in which case they are declared the winner. Since the final election varies may not be held on the standard nationwide general election day, we exclude Louisiana from all of our analysis. We also drop states in the roll-off analysis that do not report vote totals in uncontested elections which include Arkansas, Florida, Louisiana, and Oklahoma. In addition, due to a lack of available county-level Congressional returns in many years, we do not use Pennsylvania in the roll-off elections either.

Finally, there are two elections that meet all of criteria discussed above or earlier in the text that we still drop. The Arkansas 1990 senatorial election is dropped because counties do not report vote totals due to the fact under state law election results for unopposed elections need not be reported. The Georgia 1992 Senate final election was a runoff election held on November 24th since no candidate received at least 50 percent of the vote on November 3rd.

We obtained data for state House of Representative elections for 1968-1989 from ICPSR (ICPSR 1992). These elections generally occur every two years although there are some exceptions. An important consideration that arises with the use of State House elections is the prevalence of multimember districts. Constituents in multi-member districts can vote for more than one candidate which means that using total votes cast to determine turnout is problematic for counties that contain such districts. Therefore, we restrict our examination of State House elections to states which contain only single member districts in both years used for each first difference observations. Our final sample for this analysis makes use of counties in thirty-two states that can contribute at least one first-difference observation.

Data Source for data on State Legislative Returns: Inter-university Consortium for Political and Social Research. STATE LEGISLATIVE ELECTION RETURNS IN THE UNITED STATES, 1968-1989 [Computer file]. Fifth ICPSR ed. Ann Arbor, MI: Inter-university Consortium for Political and Social Research [producer and distributor], 1992.

Data Source for turnout data: Inter-university Consortium for Political and Social Research. GENERAL ELECTION DATA FOR THE UNITED STATES, 1950-1990 [Computer file]. Fifth ICPSR ed. Ann Arbor, MI: Inter-university Consortium for Political and Social Research [producer and distributor], 1995.

\section{Defining Coal and Oil States and County Employment Share in Oil and Coal}

We construct a measure of the importance of the oil and gas industry and the coal industry in the various counties within these states using County Business Patterns (CBP). Since 1974, CBP data have been based on the Census Bureau's Standard Statistical Establishment List. Because of the risk of disclosing firm specific information, exact employment numbers for two-digit industries such as coal and oil and gas are not available at the county-level. However, the CBP provides county-level information on both the number of firms in each two-digit industry and the number of 
firms that fall into a specific firm-size category (e.g., 20 to 49 employees) for these industries. By weighting the number of firms in a firm-size category by the mid-point of the number of employees in that category, we create an estimate of the number of employees in each two-digit industry at the county-level. We then create county-level estimated employment shares by industry as the ratio of the estimated industry employment to the estimated total county employment where the total county employment is also estimated by using the firm-size methodology.

CBP data for 1970-1976 were obtained from UCLA's Institute for Social Science Research Data Archive through the kind help of Libbie Stephenson. CBP Data for 1977-1996 and 1998-1999 was obtained from ICPSR with the remaining years being obtained from the U.S. Census Bureau.

CBP data for 1967 were obtained from the University of Wisconsin's Data and Information Services Center through the kind help of Cynthia Severt.

\section{Microdata from the American National Election Survey (ANES)}

We use microdata from the 1948-2004 American National Election Studies (ANES) Cumulative Data File (American National Election Studies 2011) which is ICPSR Study no. 8475. For our cross-sectional analysis, we restrict the sample to observations with non-missing data for gender, age, and employment status. For our panel analysis, it is important to note that the ANES includes one observation per household in each survey although that the same individual from the household may not be interviewed in all both periods. We use the following approach to link individuals the two observations for an individual which are spaced four years apart. We first use the unique household identifier variable VCF0006A to link observations from the same household across the two survey waves. We then only use linked observations for the same household if a) the respondents gender is the same across both waves and b) the difference in the respondents age between the two survey waves is within two years of the expected four year age difference (i.e., the age change is between two and six years). The respondents gender is the same in over 99 percent of the linked household observations while the age difference is between two and six years in over 96 percent of the linked household observations (over $93 \%$ of the age differences are between three and five years while $81 \%$ of observations have exactly a four year age difference).

\section{Census County-Level Migration Data}

We obtain county-level migration rates using the Summary Tape File 4 data of the 1970, 1980, and 1990 Censuses, made available through the National Historical Geographic Information System. In each of these Census years, a sample of households is asked whether each household member lived in the same house five years before the Census date and, for each one that did not, the county, state, and/or country of residence five years earlier is ascertained. The fraction of the population sampled for this question is $15 \%$ in 1970, $19 \%$ in 1980, and $17 \%$ in 1990. The Census Bureau then creates county-level estimates on the number of migrants based on these responses. The full Census is used to enumerate the number of persons ages 5 and over that reside in the county as of the Census date. The Census Bureau imputes age and place of residence five years earlier if the necessary information is missing or incomplete on the Census form. We only use the non-allocated (i.e., non-imputed) counts to compute county-level migration rates. 
Appendix Table 1 -Top Twenty Five Mining States By 1974 CBP Employment Shares

\begin{tabular}{|c|c|c|c|c|c|}
\hline & \multirow{2}{*}{$\begin{array}{l}\text { Percent of } \\
1974 \text { CBP } \\
\text { Employment } \\
\text { from Mining }\end{array}$} & \multicolumn{2}{|c|}{$\begin{array}{l}1974 \text { CBP Share of } \\
\text { mining establishments } \\
\text { found in: }\end{array}$} & \multicolumn{2}{|c|}{$\begin{array}{l}1967 \text { CBP Share of } \\
\text { mining establishments } \\
\text { found in: }\end{array}$} \\
\hline & & Oil and Gas & Coal & Oil and Gas & Coal \\
\hline Wyoming & $15.8 \%$ & $77 \%$ & $5 \%$ & $82 \%$ & $3 \%$ \\
\hline West Virginia & $13.3 \%$ & $40 \%$ & $53 \%$ & $47 \%$ & $48 \%$ \\
\hline New Mexico & $7.8 \%$ & $82 \%$ & $1 \%$ & $76 \%$ & $2 \%$ \\
\hline Louisiana & $5.9 \%$ & $88 \%$ & $0 \%$ & $91 \%$ & $0 \%$ \\
\hline Montana & $4.3 \%$ & $66 \%$ & $5 \%$ & $68 \%$ & $4 \%$ \\
\hline Kentucky & $4.3 \%$ & $16 \%$ & $74 \%$ & $35 \%$ & $54 \%$ \\
\hline Arizona & $4.1 \%$ & $21 \%$ & $2 \%$ & $12 \%$ & N/A \\
\hline Alaska & $3.9 \%$ & $70 \%$ & $3 \%$ & $63 \%$ & $7 \%$ \\
\hline Oklahoma & $3.9 \%$ & $90 \%$ & $1 \%$ & $92 \%$ & $0 \%$ \\
\hline Utah & $3.7 \%$ & $47 \%$ & $5 \%$ & $32 \%$ & $10 \%$ \\
\hline Texas & $3.2 \%$ & $88 \%$ & $0 \%$ & $92 \%$ & $0 \%$ \\
\hline Colorado & $2.2 \%$ & $58 \%$ & $6 \%$ & $50 \%$ & $9 \%$ \\
\hline Nevada & $2.1 \%$ & $14 \%$ & N/A & $10 \%$ & N/A \\
\hline Kansas & $1.8 \%$ & $85 \%$ & $1 \%$ & $87 \%$ & $0 \%$ \\
\hline South Dakota & $1.7 \%$ & $21 \%$ & $\mathrm{~N} / \mathrm{A}$ & N/A & $\mathrm{N} / \mathrm{A}$ \\
\hline Idaho & $1.6 \%$ & $10 \%$ & N/A & $\mathrm{N} / \mathrm{A}$ & $\mathrm{N} / \mathrm{A}$ \\
\hline Virginia & $1.4 \%$ & $4 \%$ & $67 \%$ & $2 \%$ & $73 \%$ \\
\hline Pennsylvania & $1.2 \%$ & $25 \%$ & $50 \%$ & $27 \%$ & $55 \%$ \\
\hline North Dakota & $1.2 \%$ & $65 \%$ & $15 \%$ & $61 \%$ & $18 \%$ \\
\hline Mississippi & $1.1 \%$ & $81 \%$ & N/A & $83 \%$ & N/A \\
\hline Minnesota & $1.1 \%$ & $9 \%$ & $1 \%$ & $5 \%$ & $0 \%$ \\
\hline Alabama & $1.0 \%$ & $23 \%$ & $34 \%$ & $10 \%$ & $47 \%$ \\
\hline Arkansas & $0.8 \%$ & $66 \%$ & $3 \%$ & $67 \%$ & $4 \%$ \\
\hline Tennessee & $0.7 \%$ & $9 \%$ & $41 \%$ & $4 \%$ & $43 \%$ \\
\hline Ohio & $0.7 \%$ & $39 \%$ & $20 \%$ & $43 \%$ & $22 \%$ \\
\hline
\end{tabular}

Notes: States in bold are "Oil States" in our analysis; States in italics are "Coal States" 
A. 1974 County Oil and Gas Employment Share in Oil States

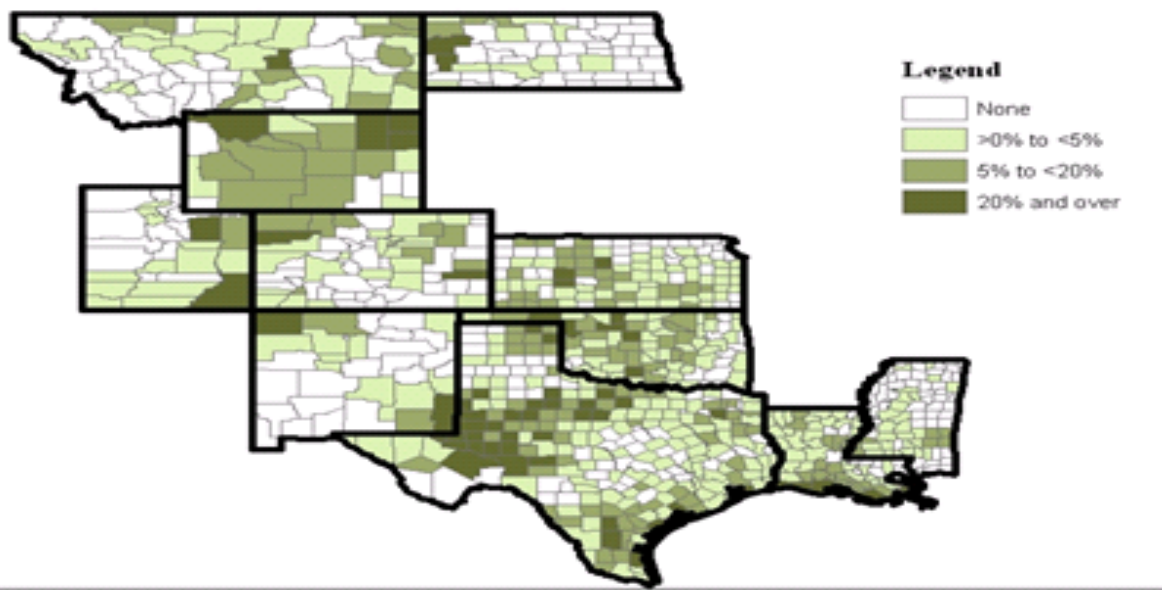

B. 1974 County Coal Employment Share in Coal States

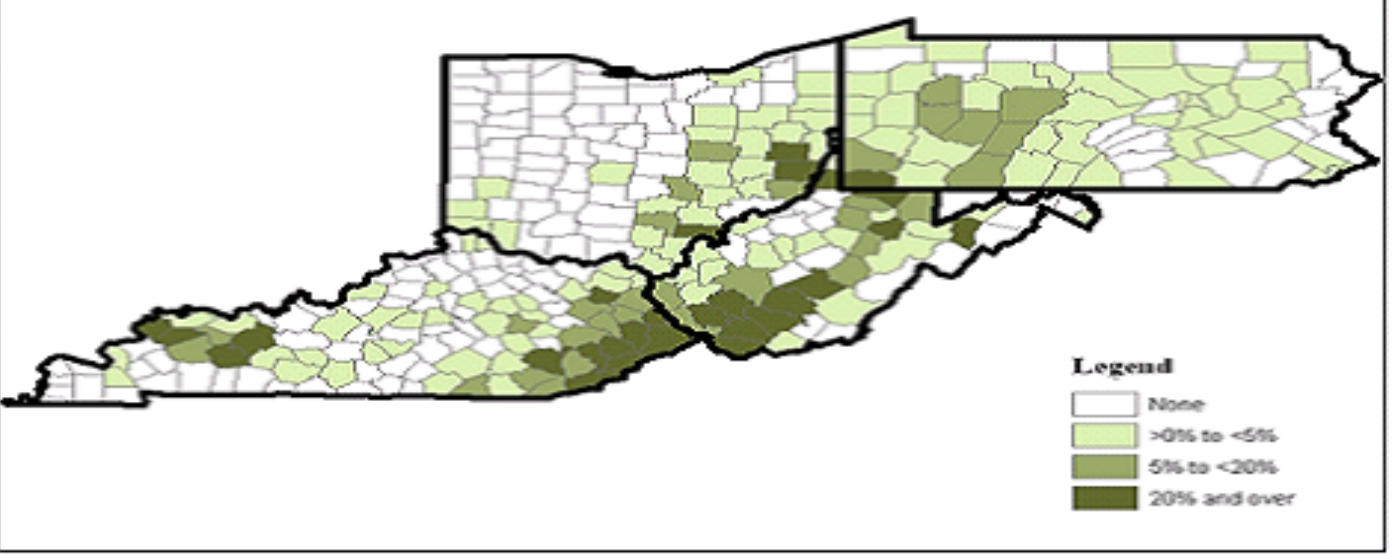

Appendix Figure 1. Distribution of Small, Medium and Large Producing Counties in "Oil" and "Coal" States. 


\section{Theory Appendix: Overview of Link Between Labor Market Activity, Information and Voting}

Existing theoretical work suggests that voters confront two types of voting costs: logistical cost of voting, $C_{L}$, such as standing in line or driving to the polls; and various costs associated with the lack of knowledge associated with derive from limited information, which we denote uncertainty costs, $C_{U}$. Suppose that these two types of voting costs depend on a voter's labor market activity, $0<h<1$. Specifically, suppose that at date $t$ in location $k$ there are specific set of logistical challenges $g(t, k)$, such as traffic or weather. The logistical cost faced by a voter at that place and time may be written as

$$
C_{L}=a h g(t, k)+\varphi
$$

where $\varphi$ represents idiosyncratic individual factors. The parameter $a>0$ captures the fact that logistical hurdles impose greater burdens on persons more heavily involved in market work. Let a voter's uncertainty costs depend on the information generally available about an election $e$ occurring at a given time and place, $I(e, t, c)$; and by the voter's exposure to that political information, which we assume varies negatively with his labor market activity. Of course, people may also get information about politics at work. We argue merely that leisure activities like watching the media, talking to friends and attending political events likely provide more information than that from co-workers. Let uncertainty costs be written

$$
C_{U}=-(1+b h) I(e, t, k)+\zeta
$$

where $\zeta$ represents idiosyncratic determinants of uncertainty. The parameter $-1<b<0$, implying that increases in available information lower uncertainty costs, with an effect that is smaller the more time the voter spends on market work rather than on leisure-intensive activities like consuming media.

Let $\omega=\zeta+\psi$ represent all the idiosyncratic determinants of a voter's voting costs. The standard Downs models assumes that a citizen votes if benefits exceed costs - that is when $D>C_{L}+C_{U}$. The probability that a citizen votes (or, equivalently, the share of citizens who vote), $V_{k t}^{e}$ is given by

$$
V_{k t}^{e}=F_{\omega}(D-h(a g(t, k)-b I(e, t, k)))
$$


where $F_{\omega}$ is the cdf of the distribution from which $\omega$ is drawn. For illustrative simplicity, assume $\omega$ is distributed Uniform $[0,1]$. Then, from $(3 \mathrm{~A})$, the marginal effect of greater labor market activity on turnout is

$$
\frac{\delta V_{k t}^{e}}{\delta h}=-(-(a g(t, k)-b I(e, t, k))) \leq 0
$$

Expression (4A) says that there should be a negative (or at least, non-positive) relationship between labor market activity and turnout in a given local area, and that this effect should differ across elections for which there is a priori reason to suppose there are differences in available information, as summarized by $I(e, t, k)$.

In general, $(4 \mathrm{~A})$ combines the effect of work activity operating through logistical costs and the effect operating through information exposure. Notice, however, that if there were two elections, say $e$ and $\bar{e}$ occurring at precisely the same time within a given location and appearing on the same ballot, the effect of an increase in labor market activity on the difference in turnout across those elections could not be a function of any logistical voting hurdles since these are precisely the same for the two elections. That is,

$$
\frac{\delta V_{k t}^{e}-V_{k t}^{\bar{e}}}{\delta h}=-(a g(t, k)-b I(e, t, k))+(a g(t, k)-b I(e, t, k))=b(I(e, t, k)-I(\bar{e}, t, k))
$$

depends only on the difference in available information about the two elections. The number of people who "roll-off" between a more versus less noteworthy election on the same ballot the difference $V_{k t}^{e}-V_{k t}^{\bar{e}}$ - should get larger as labor market activity increases. This effect is due exclusively to the effect of labor market activity on uncertainty costs and would have nothing to do with logistical costs. 
Online Appendix 


\section{Online Appendix: Robustness Tests and Migration}

\section{Means}

Online Appendix Table 1 presents the summary statistics of turnout for the five types of elections studied in the paper in the the oil and coal state sample, over the period of the boom and bust studied in the TSLS analysis.

\section{Instrument Specifications}

Online Appendix Table 2 shows estimates for the TSLS estimates for the state-wide elections, using alternative definitions of the instrument. Two results are shown. We use changes in coal and oil price instead of changes in national employment in oil and coal. Also, the main specification defines the importance of oil and coal production in a county using CBP data from 1974, which is the earliest years for which two-digit data are available. Because these 1974 numbers might partly reflect endogenous responses to oil shocks (the first of which occurred in 1972/73), in the robustness test we use one-digit $1967 \mathrm{CBP}$ data to create an alternative measure of the importance of county oil and coal employment. As the table shows our results are robust to these alternative ways of defining the instrument.

\section{Larger Spatial Areas}

In another robustness exercise, we estimate OLS difference models similar to (2) in the paper, but use data for geographic areas larger than counties: State Economic Areas (SEA) and Economic Sub Regions (ESR). SEAs are aggregate economic units originally developed for the 1950 Census which consist of either a single county or a set of contiguous counties which do not cross state lines (Bogue 1951), and ESRs are aggregations of SEAs. Most states have between 6 to 11 times the number of SEAs as counties. In these models, we do not use TSLS so there is no concern that the results are contaminated by any potential failure of the exclusion restriction in those models (the possibility that energy shocks changed voting through mechanism other than labor market activity). At the same time, data from these larger geographic areas are likely to be less contaminated by measurement error problems, which is one of the key problems the TSLS models are intended to address. Also, since SEAs and ESRs are subsumed within states, OLS models using these data can 
control for statexyear fixed effects, which we have shown to be important determinants of turnout. A limitation of OLS models performed on these larger geographic units is that it is not possible for formally account for the various local (county-specific) unobserved factors, $\delta_{c}$, that clearly affect turnout. Despite these concerns, it is instructive to see how OLS regressions based on data from larger geographic areas compare to our preferred TSLS county-level results. Online Appendix Table 3 shows these results. On the whole, even though the results are somewhat more imprecise, using this more aggregated data to estimate OLS difference models with state $\times$ year fixed effects yield results broadly consistent with the state-wide results in the paper: negative effects on turnout of labor market activity in gubernatorial and senatorial elections, but presidential turnout that is either unaffected or slightly increased, by changes in labor market activity.

\section{Migration}

An important consideration that might affect the causal interpretation we place on the results in the paper is transitory internal migration associated with local economic shocks. Suppose that migrants sort temporarily into areas where labor market conditions are improving. Suppose further that migrants do not vote in elections dominated by local concerns because they are either unfamiliar with those concerns or regard them as irrelevant, given their temporary residence in the area. Finally, suppose that migrants continue to vote in elections whose outcomes are relevant to them wherever they live in the future. Local labor market activity and voter turnout would then be negatively related in gubernatorial or senatorial elections, the outcomes of which are relevant only for people who are from or plan to live in the state in the future. At the same time, these same variables might exhibit no systematic relationship to turnout in presidential elections, about which voters are presumably interested wherever in the country they live. In this scenario, the TSLS estimates could be identifying the effect of migration associated with energy shocks rather than how labor market activity changes turnout among a given set of voters.

We estimate negative effects of labor market activity on turnout for gubernatorial and senatorial elections. For these two elections, the migration concern is important only insofar as migration is from outside the state; migrants across different counties within a state presumably care about the outcomes of these two state-wide elections. Fortunately, we can study within- and out-of-state migration over the period of the energy price shocks.

The interval of what we have called the energy "boom" and "bust" over which the TSLS results 
are estimated is approximately 1970 to 1990. This is fortunate, as we can use the question from the 1970, 1980 and 1990 Censuses about where the respondent lived five years previously to determine how the share of the population new to a county changed across oil and coal counties over the energy "boom" (1970-1980) and "bust" (1980-1990) periods. These measures are available at the county-level in Census summary files. The first two columns in Online Appendix Table 4 show how the share of residents who had lived in a different county five years previously changed differentially in large and medium, compared to small counties. We find that during the boom, large and medium coal and oil producing counties experienced increases in the share of their residents who had lived in a different county five years previously, and that these counties experienced a reduction in the share of such persons during the period of the energy bust. Again, these estimates represent comparisons to small producing counties - precisely the comparisons on which the TSLS estimates are based.

The results in the second pair of columns, which examine the change in the share of a county's residents who lived in another state five years previously, reveal a different pattern. We find that during the energy boom there was no statistically significant change in oil or coal counties' shares of out of state residents compared to changes in small producing counties. And, the reduction in the share of state migration during the bust was only a fraction of the overall relative reduction in the share of persons who from another county. Thus, whereas the energy supply shocks did indeed occasion greater in- and out-migration into the "large" and "medium" oil and coal producing counties compared to "small" ones, the overwhelming majority of that relative migration difference involved people from within the state. Given this, and presuming that all residents of a state have an interest in state-wide elections irrespective of which county they live in, these results suggest that the negative gubernatorial county results are not driven by migration.

We can bound the possible effect of migration on the TSLS turnout estimates over the boom (when there was no relative out of state migration difference into small, medium and large counties) and bust (when the statistically significant out-of-state migration differences are small). Suppose we make the unrealistic assumption that all out of state migrants into a county do not vote in gubernatorial elections because they did not know or care about these elections in the state to which they move. The results imply that of the 6.3 estimated percentage point change in turnout over the boom/bust cycle in large oil counties from the TSLS estimates, at most only 1.7 percentage points is attributable to migration. Similarly, for large and medium coal states, observed changes in migration cannot explain more than one-third of the 3.3 percentage point swing in gubernatorial 
turnout arising from changes in labor market activity over the boom/bust cycle in large or medium coal counties.

Unfortunately, we have no data on migration across congressional districts so cannot similarly bound the role of migration on the results in elections for the Congress and State House. 


\section{Online Appendix: Suggestive Evidence from the ANES}

We conclude our ANES analysis with some simple associational patterns that have not been presented in previous work, as far as we know. The results do not directly test the argument relating labor supply to information, media exposure and turnout but they provide some corroboration of it. The first bit of evidence examines the associational relationship between reported turnout, information and partisanship. Formal definitions of partisanship (Achen 2005) and intuition suggest that the more strongly a person identifies with a given political party the less likely he is to modify his relative preferences over candidates in the face of objective information about politics; candidates' party identification effectively becomes all he needs to know to determine which candidate he most prefers. This implies that, while there should be a negative relationship between reported turnout and how informed the person is judged by an objective observer, the negative gradient should be larger for political moderates compared to more strongly partisan voters.

ANES respondents report their political partisanship in a series of questions which are translated

to a seven point scale, ranging from "Strong Democrat"=1, "Independent" =4, through "Strong Republican"=7. The two graphs in Online Appendix Figure 1 show the share of respondents who reported having voted in the election, by the respondent's self-reported partisanship and by their levels of interviewer-assessed political knowledge and media exposure. The top two lines in each figure are the average reported turnout rate for informed and un-informed persons of the given partisanship type; the bottom line in each graph shows the difference in these two means, with $95 \%$ confidence interval bands. The figure shows that better informed persons of each partisanship type were more likely to vote, by between 1.3 and 3.2 statistically significant percentage points. The graphs also show that moderates are more sensitive to political information: the gap in turnout between informed and un-informed moderates is statistically larger than the corresponding gap for voters at the extremes of the partisanship distribution. These results are subject to the concerns we have raised about the reliability of reported turnout, but they are consistent with an information based account of voting.

The second piece of associational evidence provides some individual-level corroboration for the argument we have made for why voting in presidential elections (unlike other contests) may not affected by labor market activity. We have argued that this result makes sense in the context of an information-based model of voting if peoples' knowledge about presidential contests is vastly superior to that for other elections, and if it is so close to perfect that less exposure to political 
information has scant effect on what people know. We can test this argument directly.

For different types of elections over several survey years, ANES respondents are asked to rate the candidates in the previous election contest. This "thermometer" scale ranges from 0 to 100. We categorize respondents as not being able to "recall" a given candidate if when answering this question they either do not recognize the candidate's name or they state that they cannot judge the candidate. Valid numeric responses are categorized as "recalling" the candidate. This is the only available measure of information differences across different types of elections and is available for multiple election types beginning in 1978. It is admittedly quite coarse and is not elicited for gubernatorial elections. These shortcomings notwithstanding, we find that the share of respondents who can recall both candidates is $97 \%, 66 \%$ and $45 \%$, respectively, for presidential, Senate and House elections. Reassuringly, as we argued in the county turnout analysis, ignorance about candidates falls the more "note-worthy" (meaning, the likely more intensely covered) the election. 
Online Appendix Table 1. Mean Turnout from 1969-1990, by Election Type, Across Coal and Oil States in U.S. (Standard Deviations in Parentheses).

\begin{tabular}{cccccc}
\multicolumn{2}{c}{ "State-Wide" Elections } & & \multicolumn{2}{c}{ "Local" Elections } \\
\cline { 1 - 2 } President & Governor & Senator & & U.S. Congress & State Legislator \\
$(4-Y e a r$ Cycle $)$ & $(4-Y e a r$ Cycle $)$ & $(6-$ Year Cycle $)$ & & $(2-Y e a r$ Cycle $)$ & (2-Year Cycle)
\end{tabular}

\section{Mean Turnout}

All Years

0.556

$(.079)$

0.417

(.113)

0.459

(.115)

0.424

(.146)

0.398

Presidential Years

0.641

(.091)

0.530

(.082)

0.508

(.135)

Non-Presidential Years

0.400
$(.094)$

0.398

(.103)

(.108)

0.453

Non-Presidential Years

70

$\begin{array}{cc}76 & 104 \\ 20 & 48 \\ 0.26 & 0.46\end{array}$

\subsection{5}

(.136)

Number of Elections, all Years

20
0.26

Number of elections in Presidential years

Percent of elections in Presidential years

Data drawn from multiple sources on aggregate voting data. See Data Appendix for details.

Sample means and standard deviations are weighted by number of adults. 
Online Appendix Table 2. TSLS Estimates of Change in County Labor Market Outcomes on Change in Voter Turnout under Alternative Specifications of Oil and Coal Shock Instruments in "Oil" and "Coal" States.

\begin{tabular}{|c|c|c|c|c|c|c|}
\hline & \multicolumn{2}{|c|}{ Governor } & \multicolumn{2}{|c|}{ Senate } & \multicolumn{2}{|c|}{ President } \\
\hline & \multicolumn{2}{|c|}{ Endogenous Regressor } & \multicolumn{2}{|c|}{ Endogenous Regressor } & \multicolumn{2}{|c|}{ Endogenous Regressor } \\
\hline & $\begin{array}{l}\Delta \text { County Log } \\
\text { per } \\
\text { Capita Annual } \\
\text { Earnings } \\
\end{array}$ & $\begin{array}{c}\Delta \text { County } \\
\text { Log Employment } \\
\text { per Adult } \\
\end{array}$ & $\begin{array}{c}\Delta \text { County Log per } \\
\text { Capita Annual } \\
\text { Earnings } \\
\end{array}$ & $\begin{array}{c}\Delta \text { County } \\
\text { Log Employment } \\
\text { per Adult }\end{array}$ & $\begin{array}{c}\Delta \text { County Log per } \\
\text { Capita Annual } \\
\text { Earnings } \\
\end{array}$ & $\begin{array}{c}\Delta \text { County } \\
\text { Log Employment } \\
\text { per Adult }\end{array}$ \\
\hline \multicolumn{7}{|l|}{ Instrument Specification: } \\
\hline $\begin{array}{l}\text { 1. ( } \Delta \text { National Coal/Oil Employment ) X } \\
\text { I("medium", "large" Oil/Coal 1967) } \\
\text { F-Stat on Excluded Instuments }\end{array}$ & $\begin{array}{r}-.066 \\
(.026) \\
17.4\end{array}$ & $\begin{array}{r}-.113 \\
(.064) \\
49.1\end{array}$ & $\begin{array}{r}-.042 \\
(.022) \\
13.3\end{array}$ & $\begin{array}{r}-.079 \\
(.087) \\
44.3\end{array}$ & $\begin{array}{r}.042 \\
(.024) \\
6.2\end{array}$ & $\begin{array}{r}.078 \\
(.057) \\
29.8\end{array}$ \\
\hline $\begin{array}{l}\text { 2. ( } \Delta \text { Coal/Oil Price ) X } \\
\text { I("medium", "large" Oil/Coal 1974) } \\
\text { F-Stat on Excluded Instuments }\end{array}$ & $\begin{array}{r}-.171 \\
(.029) \\
27.8\end{array}$ & $\begin{array}{r}-.352 \\
(.080) \\
38.0\end{array}$ & $\begin{array}{r}-.044 \\
(.046) \\
13.7\end{array}$ & $\begin{array}{r}-.099 \\
(.134) \\
27.7\end{array}$ & $\begin{array}{r}.050 \\
(.048) \\
15.6\end{array}$ & $\begin{array}{r}.113 \\
(.114) \\
87.2\end{array}$ \\
\hline $\begin{array}{l}\text { 3. ( } \Delta \text { Oil/Coal Price) X } \\
\text { I("medium", "large" Oil/Coal 1967) } \\
\text { F-Stat on Excluded Instuments }\end{array}$ & $\begin{array}{r}-.157 \\
(.033) \\
19.4\end{array}$ & $\begin{array}{r}-.286 \\
(.077) \\
35.3\end{array}$ & $\begin{array}{r}-.027 \\
(.036) \\
16.3\end{array}$ & $\begin{array}{r}-.078 \\
(.078) \\
15.0\end{array}$ & $\begin{array}{r}.068 \\
(.032) \\
15.1\end{array}$ & $\begin{array}{r}.137 \\
(.073) \\
47.5\end{array}$ \\
\hline $\begin{array}{l}\text { 4. ( } \Delta \text { National Coal/Oil Employment ) X } \\
\text { Continuous Measure of Coal/Oil } \\
\text { Employment Share in } 1974 \\
\text { F-Stat on Excluded Instuments }\end{array}$ & $\begin{array}{r}-.118 \\
(.048) \\
32.6\end{array}$ & $\begin{array}{r}-.271 \\
(.119) \\
22.9\end{array}$ & $\begin{array}{r}-.028 \\
(.037) \\
28.8\end{array}$ & $\begin{array}{r}-.065 \\
(.098) \\
66.7\end{array}$ & $\begin{array}{r}.023 \\
(.019) \\
14.3\end{array}$ & $\begin{array}{r}.055 \\
(.040) \\
130.7\end{array}$ \\
\hline State*Year Fixed Effects & Yes & Yes & Yes & Yes & Yes & Yes \\
\hline Observations & 4751 & 4751 & 6014 & 6014 & 4412 & 4412 \\
\hline $\begin{array}{l}\text { Each point estimate in the table represents } \\
\text { Standard errors account for arbitrary form } \\
\text { Counties are "medium" if share of employ } \\
\text { All regressions control for Change Since } \\
\text { percentage population aged } 30 \mathrm{~s}, 40 \mathrm{~s}, 50\end{array}$ & $\begin{array}{l}\text { from a different } \\
\text { ustering within st } \\
\text { n oil/coal at least } \\
\text { lection in: log to } \\
70 \text { and up }\end{array}$ & $\begin{array}{l}\text { ression. } \\
\text { but less than } 20 \% \text {; } \\
\text { opulation; percent }\end{array}$ & $\begin{array}{l}\mathrm{e} \text { " if share }>20 \% \\
\text { male adults; percen }\end{array}$ & Black adults, perc & "other" race; & \\
\hline
\end{tabular}


Online Appendix Table 3. OLS Estimates of Effect of State Economic Area (SEA)-Level and Economic Sub-Region-Level

Economic Performance on Voter Participation: Regressions for all SEAs and ESRs in U.S. for 1969-2000

Elections. First-Difference (Change Since Last Election) Models.

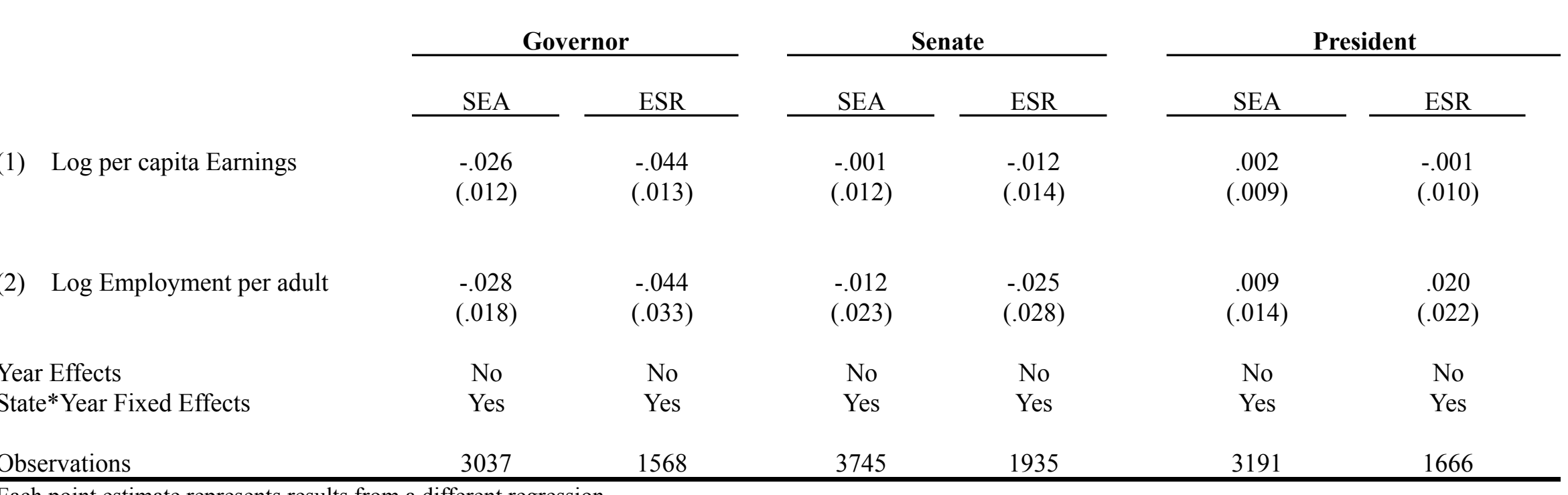

Each point estimate represents results from a different regression.

Standard errors account for arbitrary forms of clustering within states.

All regressions control for Change Since Last Election in: log total population; percentage female adults; percentage Black adults, percentage "other" race; percentage population aged $30 \mathrm{~s}, 40 \mathrm{~s}, 50 \mathrm{~s}, 60 \mathrm{~s}, 70$ and up

All regressions are weighted by the number of adults.

SEA and ESR level variables are created by summing county observations within SEAs and ESRs. 
Online Appendix Table 4. OLS Estimates of Whether Change in Share of County's Residents Living Outside County and Outside State Five Years Before, Differs across "Large", "Medium" and "Small" Production Counties in Oil and Coal States over Energy Shock "Boom" and "Bust".

\begin{tabular}{cc}
$\begin{array}{c}\text { A. } \Delta \text { County Residents who Living } \\
\text { Outside County } \text { Five Years Prior }\end{array}$ \\
\hline 1970 to $1980 \quad 1980$ to 1990
\end{tabular}

Importance of Oil/Coal in County:

\begin{tabular}{|c|c|c|c|c|}
\hline I(Medium_Coal_1974) & $\begin{array}{l}.010 \\
(.005)\end{array}$ & $\begin{array}{l}-.022 \\
(.004)\end{array}$ & $\begin{array}{l}.002 \\
(.004)\end{array}$ & $\begin{array}{l}-.013 \\
(.002)\end{array}$ \\
\hline I(Large_Coal_1974) & $\begin{array}{l}.002 \\
(.005)\end{array}$ & $\begin{array}{l}-.024 \\
(.004)\end{array}$ & $\begin{array}{l}.0001 \\
(.006)\end{array}$ & $\begin{array}{l}-.016 \\
(.004)\end{array}$ \\
\hline I(Medium_Oil_1974) & $\begin{array}{l}.022 \\
(.004)\end{array}$ & $\begin{array}{l}-.021 \\
(.004)\end{array}$ & $\begin{array}{l}.004 \\
(.006)\end{array}$ & $\begin{array}{l}-.001 \\
(.004)\end{array}$ \\
\hline I(Large_Oil_1974) & $\begin{array}{l}-.002 \\
(.004)\end{array}$ & $\begin{array}{l}-.047 \\
(.005)\end{array}$ & $\begin{array}{l}.003 \\
(.003)\end{array}$ & $\begin{array}{l}-.017 \\
(.007)\end{array}$ \\
\hline $\begin{array}{l}\text { State Fixed Effects } \\
\text { F-Stat on Oil/Coal Shock (P-Value) }\end{array}$ & $\begin{array}{c}\text { Yes } \\
8.9(0.001)\end{array}$ & $\begin{array}{l}\text { Yes } \\
36.4(<0.001)\end{array}$ & $\begin{array}{c}\text { Yes } \\
0.9(0.475)\end{array}$ & $\begin{array}{c}\text { Yes } \\
18.7(<0.001)\end{array}$ \\
\hline Observations & 1103 & 1103 & 1103 & 1103 \\
\hline
\end{tabular}

Each column in the table represents results from a different regression.

Standard errors account for arbitrary forms of clustering within states.

Counties are "medium" if share of employment in oil/coal at least 5 percent but less than 20 percent; "large" if share equals or exceeds 20 percent 1970-1980 regressions are weighted by the total population in 1980 age 5 and up.

1980-1990 regressions are weighted by the total population in 1990 age 5 and up.

\section{B. $\Delta$ County Residents who Living Outside State Five Years Prior

1970 to $1980 \quad 1980$ to 1990




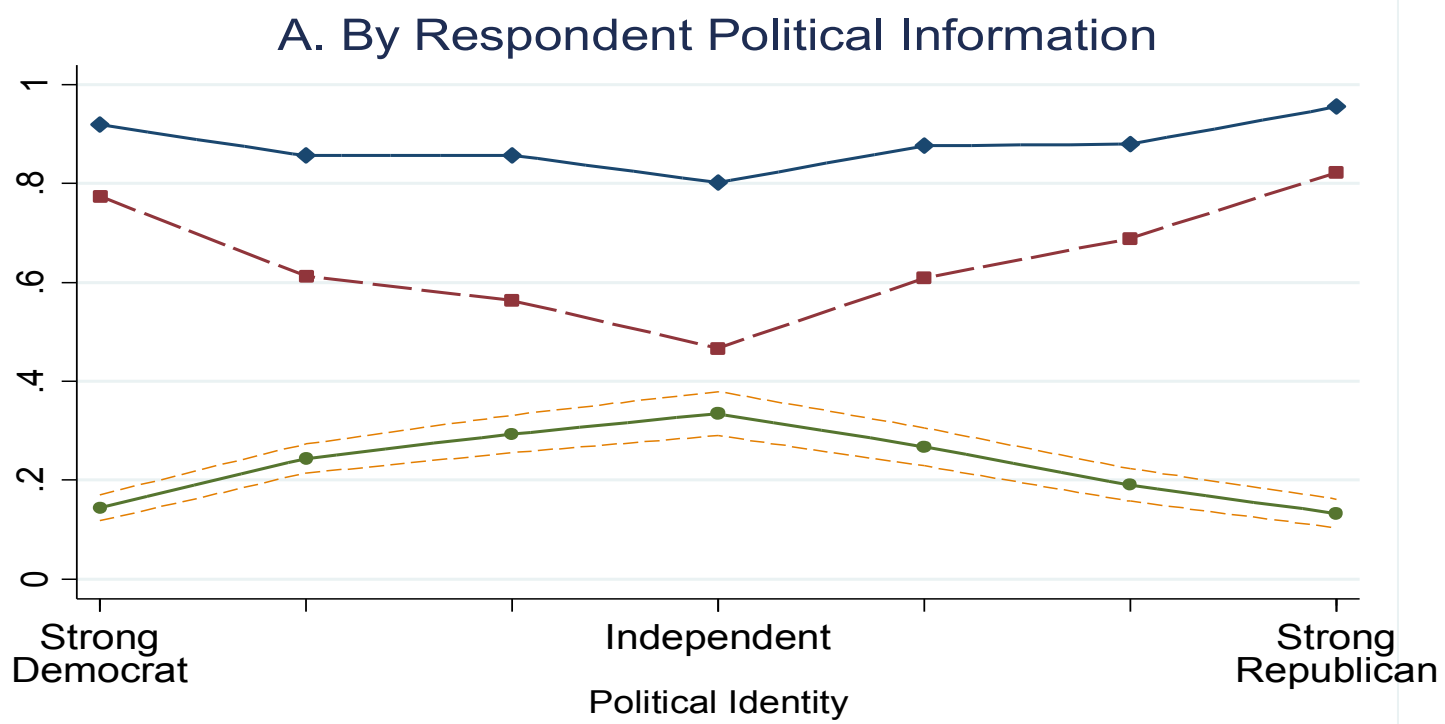

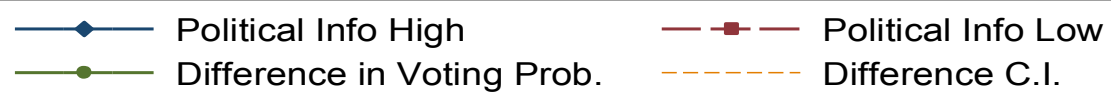

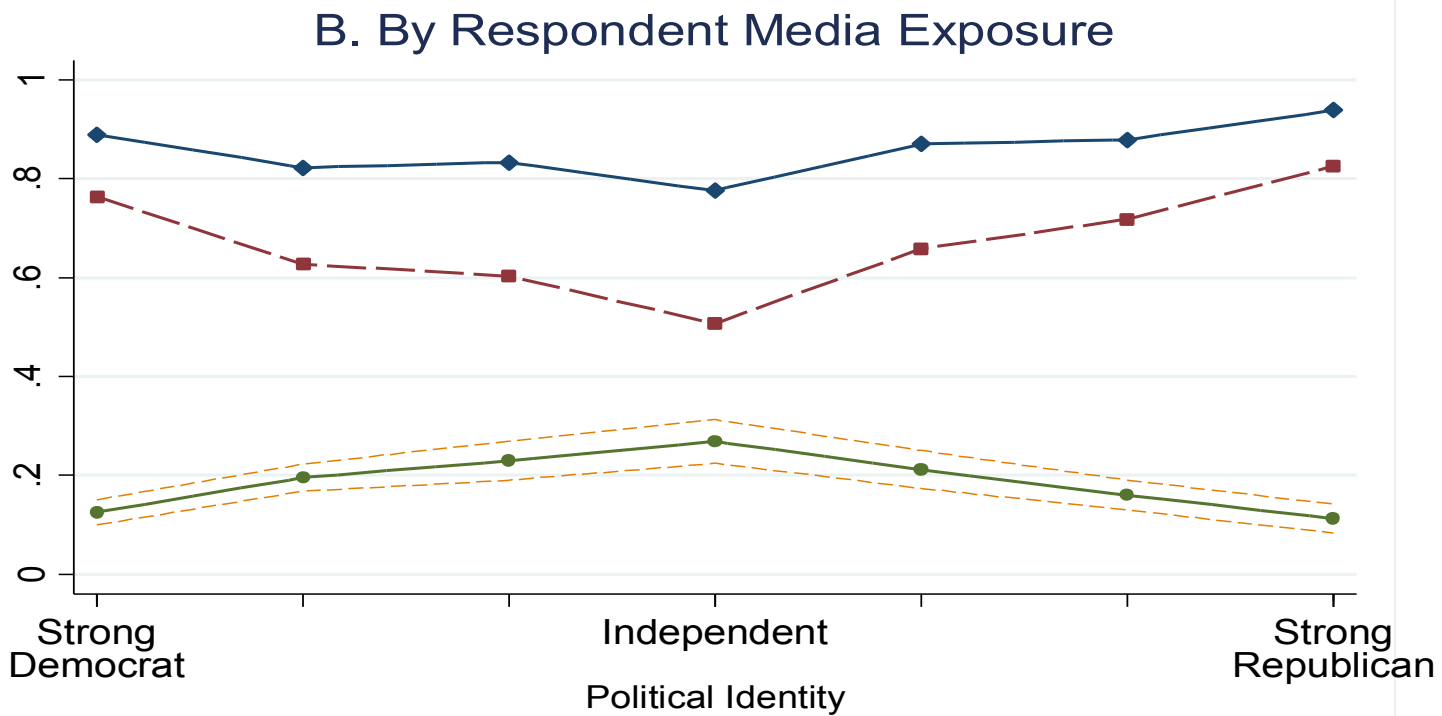

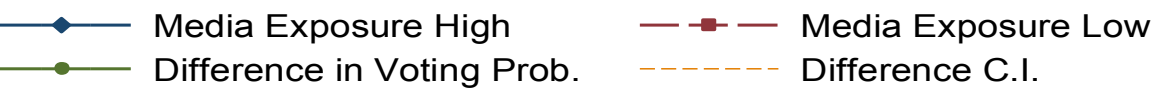

Reported Voter Participation, by Alternative Measures of Individual Partisanship

\section{Online Appendix Figure 1}

